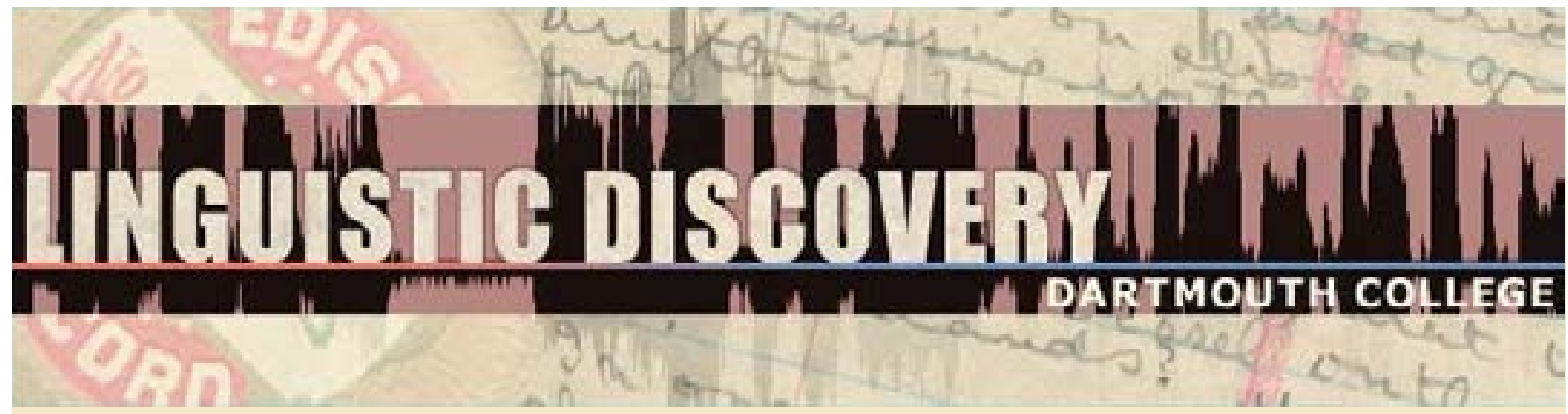

\begin{tabular}{|l|}
\hline Volume 10 \\
Issue 2 \\
2012 \\
\hline
\end{tabular}

\title{
Towards A Full Description of the Focus System in Tundra Yukaghir
}

Mark Schmalz

University of Amsterdam

doi: 10.1349/PS1.1537-0852.A.411

url: http://journals.dartmouth.edu/cgi-bin/WebObjects/ Journals.woa/1/xmlpage/1/article/411

\section{Linguistic Discovery}

Published by the Dartmouth College Library Copyright to this article is held by the authors. ISSN 1537-0852 linguistic-discovery.dartmouth.edu 


\section{Towards A Full Description of the Focus System in Tundra Yukaghir ${ }^{1}$ \\ Mark Schmalz \\ University of Amsterdam}

This paper is meant to be a contribution to a better understanding of the focus system of Tundra Yukaghir. It recapitulates the major findings that were made with respect to the topic discussed and presents a number of new empirical facts some of which contradict or form an essential addition to the preexisting views.

\section{Preliminaries}

\subsection{Intoduction}

Tundra Yukaghir (henceforward TY) is one of the two survivors, the second being Kolyma Yukaghir (henceforward KY), of a group of closely related languages spoken by the peoples (wadul/odul) that once populated the vast area of the Russian Empire between the cost of the North Polar See and the upper reaches of Yana, Indigirka and Kolyma spreading longitudinally as far as the lower reaches of Lena and upper reaches of Anadyr (Donskoj 1996:22). The ethnic designation wadul/odul, as one can learn from e.g. Kurilov (1996:112), was a cover name for at least 12 closely related tribes, comparable with the term "Slav" referring to Russians, Poles, Serbians etc. as a whole. Although the common ancestry of those tribes is apparent, their representatives normally consider themselves different peoples (Nikolaeva 2002:1). This, together with the pronounced differences in the lexicon resulting in a very reduced interintelligibility between the extant varieties of Yukaghir, TY and KY, makes it more appropriate to regard them as two separate languages than two dialects as they were viewed earlier (e.g. Krejnovič 1982:3). Nowadays only about $10 \%$ of all Yukaghirs master their language to some extent (Kurilov 1996:113) because the major means of the daily communication have been for decades Yakut and since more recent times also Russian. Even some elderly speakers of TY are so accustomed to speaking a lingua franca of the area that they resort to it even when communicating with each other. At present only five persons have full command of KY (Prokopyeva 2011, personal communication ${ }^{2}$ ), two of them living in the Republic of Sakha (Yakutia) and the other three in the neighboring Magadan region. TY is in a slightly better situation in that respect with not less than a half-dozen of competent fluent speakers of TY living in the village of Andryushkino, the settlement with the greatest number of TY speakers. At least as many can be found in the nearby tundra, settling or herding. There are, however, hardly any true TY monolinguals. Efforts to revitalize the language are undertaken. Some of the most important measures are the establishment of a national Yukaghir municipal entity in Andryushkino in 2008 and the introduction of TY lessons at the local school in the late 70's (Kurilov 1996:113).

\footnotetext{
${ }^{1}$ This research is financially supported by the Netherlands Organization for Scientific Research (NWO).

${ }^{2}$ As writing this article was nearing its completion, I received sad news that one of the persons residing in Yakutia had died in the meantime (Matić 2011, personal communication).
} 
TY is conventionally regarded as a language isolate but factually it is remotely affiliated with Uralic languages (Nikolaeva and Chelimskij 1996:155). The focus system of TY is undoubtedly its most peculiar feature, which has many times been an object of scholarly research.

As the title of this article suggests, its aim is to give an account of the TY focus system. The system has already been described by Krejnovič $(1958,1968,1982)$. His works along with the contributions by Maslova (2003c) and Kurilov (2006) form nowadays a considerable body of the descriptive sources on TY generally and on its focus system in particular. A number of scholars addressed the issue of (morphological) marking of the pragmatic category of focus in TY after it had been described by Krejnovič (1958) for the first time ${ }^{3}$ (Harms 1977; Ard 1982; Comrie 1992; Fortescue 1996; Maslova 1989a, 2005, 2006). The theoretical contributions that appeared before the turn of the century mainly drew on the data made available by Krejnovič $(1958,1982)$. However, just as the presence of 'blank spaces' on the descriptive 'map' of TY is true for TY grammar as a whole, it holds for the pragmatic category of focus specifically.

The ultimate goal of this contribution is to give a more accomplished picture of the whole focus system of TY providing new data for further research. Filling the gaps in its description and reconciliation of apparent controversies in different descriptive sources are thus two main concerns of this contribution. They can be defined more precisely in terms of the concrete research goals which are grouped in three larger blocks. These are as follows:

- means of expressing focus (studying the distributional behavior of the particle me with the view of more precise definition of its functions; focalizing $\mathrm{A}$ in general and particularly in sentences carrying a direct object; encoding of focal topics; focalizing verb modified by a modal adverb

- focus in grammatical context (focus in sentences with multiple focal constituents, focus in negative sentences, focus in passive)

- meaning of focus markers (studying contrast as a separate pragmatic function; answering the question whether the focus markers are focus markers s.s. or a device with a wider pragmatic function)

These research goals have received a varying degree of attention in the relevant literature on TY. The distributional behavior of the particle $m e$ and focus in sentences with multiple focal constituents can be counted among those that have been dealt with in a rather detailed manner in Matić and Nikolaeva (2008) and Maslova (2005) respectively. Nevertheless, as the contribution of some new interesting data in this article shows, the discussion points of these two topics have not been exhausted yet. Some other research topics were discussed either for KY, e.g. the functional scope of the focus markers (Maslova 1997), the other Yukaghir language, or presented equivocally, e.g. focalizing A in Krejnovič (1958, 1982), Kurilov (2006) versus Kurilov (2001). Yet other issues constituting the research goals of this presentation have merely been touched upon or hardly addressed at all. This concerns especially the focus in the passive and in negative

\footnotetext{
${ }^{3}$ It will be noted here that in his earlier work (Krejnovič 1958:41) did not use the term 'focus' in this connection, but rather the label logičeskoe udarenie meaning the singling out of the constituent that represents "the main subject of the thought and utterance". It is clear that such a salient subject does not have to be new, or focal. Only in his later work Krejnovič (1982:175f.) gives this phenomenon another label: aktual'noe členenie predloženija. The key notions that he invokes in this connection are 'rhema' and the opposition 'known or inferable' vs. 'unknown', which have to do with the information structure and focus. A few pages later Krejnovič (1982:179), defines the phenomenon of morphological marking of the focus as "emphasizing important parts of an utterance".
} 
sentences. As for the latter, it was wrongly concluded that the focus oppositions were neutralized (Comrie 1992), while, quite on the contrary, the focus system operates in them in an almost unchanged way as is demonstrated by the examples contained in the present article. A special issue of the TY focus system brought to the attention of linguists here, to my knowledge, for the first time, is the variation of its usage in individual speakers of TY.

Before the research goals are treated, an overview of TY focus system is given in section 1.2. Section 1.3 presents the basic notions of information structure as they are employed in this article. The approach chosen to study the information structure of TY is described there as well. A short presentation of other methodological issues of rather technical nature is given in section 1.4. Section 2 deals with $\mathrm{SAs}^{4}$ having the single pragmatic function of focus. It is designed as if consisting of three parts: sections 2.1 to 2.3 illustrate the focus system in sentences with a single focal constituent; sections 2.4 to 2.6 describe the situation in those with multiple focal elements and section 2.7 forms a conclusion containing generalizing remarks on the focus articulations of TY. Section 3 is dedicated to SAs with multiple pragmatic functions: focal topics (section 3.1) and instances of contrast (section 3.2). One of the most enigmatic devices of the TY focus system, the verbal clitic me, becomes the subject of discussion in section 4 . This is followed by section 5 on the focalization of verbal predicates modified by qualitative adverbs. In section 6 the functional scope of the focus markers of TY is discussed. Sections 7 and 8 describe focus in negative sentences and focus in passive respectively. Paradigmatic deviations encountered in modern speakers are discussed in section 9. The results of the present study are summarized in the conclusion in section 10.

\subsection{Overview of the TY focus system}

The focus system of TY is fascinating for several reasons. Its primary linguistic devices are morphological and their employment is highly grammaticalized. The nominal focus markers show a very unusual ergative distributional pattern. The predicate participates in focus marking of the arguments by taking 'focal agreement suffixes' (Matić and Nikolaeva 2008:2) and focus on the predicate is overtly marked. The combination of these features, each of which by itself could be sufficient to attract the linguist's attention, makes the TY focus system an intriguing research object, especially from the typological perspective. Some of the most basic morphosyntactic properties of this language, i.e. the encoding of the core syntactic relations S, A and $\mathrm{O}$, depend on the given focal pattern of a sentence. Therefore, for understanding TY grammar as such, it is crucial to fully understand its focus system.

The focus system of TY is characterized by a number of formal and distributional features. The focus markers as such are the verbal proclitic mer=, the nominal suffix -ley and the pronominal suffix $-e k^{5}$. The focus markers show complementary distribution, thus only one constituent in a sentence can be marked for focus. The focal constituent is reflected in the verbal agreement endings different for intransitive and transitive verbs. Focus on the subject leads to a dramatic loss of finiteness in the verb as out of the 6 personal endings only the one distinguishing 3PL is left. The nominal ${ }^{6}$ focus markers show an ergative distributional pattern with marked $\mathrm{S}$ and $\mathrm{O}$ on one hand and unmarked $\mathrm{A}$ on the other hand. The ergativity is thus split, the conditioning factor being the pragmatic function of the argument, i.e. \pm focus.

\footnotetext{
${ }^{4}$ SA stands for 'Subact' in terms of Hengeveld and Mackenzie (2008)

${ }^{5}$ Modified focal nouns receive pronominal focus marking. (Krejnovič 1958:46)

${ }^{6}$ The same is true for the pronominal focus markers in $1^{\text {st }}$ and $2^{\text {nd }}$ person.
} 
The following overview of the TY focus system is briefly sketched after Comrie (1981a:259) and Krejnovič $(1958: 131,133,146,152)^{7}$.

Intransitive $(u u(l)$ 'to go')

Verb focus

\begin{tabular}{|c|c|c|c|}
\hline \multirow[t]{4}{*}{ SG } & 1 & met & $m e r=u u-j e \eta^{8}$ \\
\hline & 2 & tet & $m e r=u u-j e k$ \\
\hline & 3 & tudel & $m e r=u u-j$ \\
\hline & & ködey & $m e r=u u-j$ \\
\hline \multirow[t]{4}{*}{ PL } & 1 & mit & mer $=u u-j e l i$ \\
\hline & 2 & tit & $m e r=u u-j e m u t$ \\
\hline & 3 & tittel & $m e r=u u-\eta i$ \\
\hline & & čiin & $m e r=u u-\eta i$ \\
\hline
\end{tabular}

Transitive ( $a i$ 'to shoot') Verb focus

$\begin{array}{llll}\text { SG } & 1 & \text { met } & \text { mer }=a i-\eta \\ & 2 & \text { tet } & \text { mer }=a i-m e k \\ & 3 & \text { tudel } & \text { mer }=a i-m \\ & & \text { ködey } & \text { mer }=a i-m \\ \mathrm{PL} & 1 & \text { mit } & \text { mer }=a i-j \\ & 2 & \text { tit } & \text { mer }=a i-m k \\ & 3 & \text { tittel } & \text { mer }=a i-\eta a \\ & & \text { ciij } & \text { mer }=a i-\eta a\end{array}$

Object focus

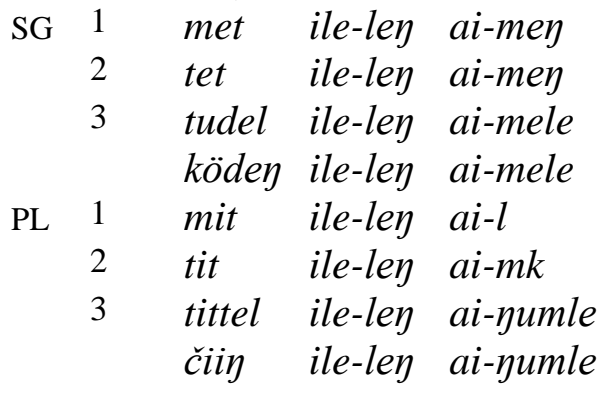

Subject focus

met-ek uu-l

tet-ek uu-l

tudel uu-l

ile-ley uu-l

mit-ek uu-l

tit-ek uu-l

tittel uu- $\quad u u-l$

ilepe-ley uи- $и u-1$

\subsection{Information structure}

\section{Subject focus}

$\begin{array}{ll}\text { met } & a i \\ \text { tet } & a i \\ \text { tud } & a i \\ \text { köde } & a i \\ \text { mit } & a i \\ \text { tit } & a i \\ \text { titt } & a i-\eta u \\ \text { čii } & \text { ai- } y u\end{array}$

Every sentence has, apart from its syntactic structure, an information structure. Syntax operates with more or less abstract grammatical categories like subject, object, predicate etc. and describes the laws according to which these categories interrelate. The universal status of some of these categories is questioned sometimes or at least they might have to be defined differently depending on the language under scrutiny. However, the notions of information structure have to

\footnotetext{
${ }^{7}$ The word ile in the following table means 'reindeer', the word ködey and its suppletive plural form čiin mean 'man' and 'people' respectively.

${ }^{8}$ In contrast to Comrie and Krejnovič, I regard the morpheme me as a clitic.
} 
do with knowledge and awareness, which rather pertain to the realm of psychology and are characteristic of all humans.

Information structure is basically the way in which an utterance is organized by the speaker with respect to the presumed state of knowledge and/or awareness of the addressee. As Lewis (1979:339) rightly notes, "at any stage in a well-run conversation, a certain amount is presupposed". Therefore, in a discourse a sentence normally begins with a constituent carrying a piece of information that is shared by the interlocutors to establish a point of departure, or 'common (back)ground' in terms of Stalnaker (1974:199), and continues with the constituents that carry information that is presumed by the speaker (S) to be unknown to the addressee (A).

These two types of information - given and new - are analyzed in FDG (Hengeveld and Mackenzie 2008:89, 92) as belonging to two different dimensions of discourse: Topic vs. Comment and Focus vs. Background.

Dik (1978:130) defines constituents with Topic function as those presenting "the entity 'about' which the Predication predicates something in the given setting". There is a strong link between the notions of 'givenness' and 'topic' although they do not coincide. The given information is normally contained in topics, or subjects which statements are made about, and constitutes the background of statements. "Given the basic function of Topics of relating the Communicated Content to existing information in the Contextual Component" (Hengeveld and Mackenzie 2008:92), it is not surprising that, as in the present work too, the term 'topical' sometimes substitutes for the term 'given'.

The new information contained in the comment is, according to Dik (1997:326), the difference between the pragmatic information of the speaker himself, or $\mathrm{P}_{\mathrm{S}}$, and the speaker's picture of the pragmatic information of the addressee, or $\left(\mathrm{P}_{\mathrm{A}}\right)_{\mathrm{S}}$. This difference constitutes the Focus of an utterance as opposed to the Background, which is presupposed, and the constituents expressing this difference are called 'focal' ${ }^{9}$. Hengeveld and Mackenzie (2008:89) add that Focus represents "the Speaker's strategic selection" of new information, which implies that whenever focus is involved, there is a possibility of an alternative. The indication of "the presence of alternatives that are relevant for the interpretation of linguistic expressions" is seen by Krifka (2008:248) as the main functional and definitive characteristic of focus.

Another important dimension of information structure is the dichotomy Contrast vs. Overlap. Contrast, its by far more important member, "signals the Speaker's desire to bring out the particular differences between two or more Communicated Contents or between a Communicated Content and contextually available information" (Hengeveld and Mackenzie 2008:96). In this article only the former, marked members of the Focus-Background and Contrast-Overlap dichotomies will be studied because topics remain unmarked ${ }^{10}$ in TY.

Syntactic and pragmatic structures do not coincide in many languages. If analyzed syntactically, the sentence "I am writing an article on the focus system of TY." can be said to convey only one message, which becomes fully clear when the reader arrives at the dot following the linear order of the constituents of the sentence. But from the point of view of information structure this very sentence can be organized in different ways depending on the packaging of

\footnotetext{
${ }^{9}$ The idea of the divergent informational states of the interlocutors plays an important role in the definitions of the pragmatic function of focus. Lambrecht (1994:222) defines focus in a similar way as the "semantic component of a pragmatically structured proposition whereby the assertion differs from the presupposition".

${ }^{10}$ The suffix -lede can accentuate the topic of a sentence but its employment does not influence the morhosyntactic structure of a sentence (Krejnovič 1982:228). Besides, it seems to be a general emphasis marker for (pro)nominal constituents irrespective of their pragmatic function in a sentence (Krejnovič 1982:229-230).
} 
information, or on the way "in which a speaker accommodates his speech to temporary states of the addressee's mind" (Chafe 1976:28). A pitch accent on the italicized constituent in the following sentences clearly signals that the corresponding constituent is focal and serves to point out to the addressee that he was unaware of a certain relation, adding to or correcting/replacing his pragmatic information.

$I$ am writing an article on the focus system of TY. I am writing an article on the focus system of TY. I am writing an article on the focus system of TY. I am writing an article on the focus system of TY. I am writing an article on the focus system of TY. I am writing an article on the focus system of $T Y$.

Unlike the message derived from the syntactic analysis, the message conditioned by information structure becomes clear, at least partly, even before the addressee hears the end of the sentence if the focal constituent occurs early in the sentence: the addressee becomes aware of its focal status as soon as he hears it.

TY presents a relatively rare example of a language in which syntactic and informational structure do coincide. In many languages a certain information structure can be encoded with differential morphosyntactic means (e.g. cleft-sentences in English). However, in TY a certain information structure must be encoded with the corresponding morphosyntactic means. The formal realization of this obligatory interdependence is to be explored in the following sections.

The easiest way to determine how a syntactic constituent is focalized is to design a question that would imply an information gap that can be filled by naming a referent of the constituent fulfilling the same syntactic function in the answer as the question word in the question. ${ }^{11}$ In fact, this, along with the construal of the contrastive meaning, is the only constellation in which the focus marking is obligatory in TY (Maslova 2005) and thus represents a reliable way to study the focus patterns of TY. Therefore, to accomplish the above stated research goals, a number of specific questionnaires as well as isolated sentence pairs or single sentences with a particular structure were used. Before the specific research goals could actually be dealt with, a basic questionnaire (see Appendix) had to be applied in interviews with a number of potential informants in order to study what is believed to have been well established, namely the basic focal patterns of TY already described by Krejnovič $(1958,1968,1982)$. This was necessary for two reasons. First of all, at some points quite a few informants deviate considerably from what could be expected according to Krejnovič's $(1958,1968,1982)$ descriptions (see section 9). This presents a major source of interpretational difficulties. The discrepancies could have various possible reasons: influence of the lingue franche of the area, dialectal differences, shift in the focus system or even its deterioration conditioned by the decreasing level of mastery of the language. The latter was the second reason to go with every available informant through the basic questionnaire in order to assess his or her value and reliability as a potential informant in the future. Working with the basic questionnaire was useful also because some of the research goals could either be directly studied with its help (focalizing A) or be shed some light upon

\footnotetext{
${ }^{11}$ With predicates, which, of course, do not have referents, the information gap is filled by naming the action performed.
} 
(usage and function of the clitic $m e(r){ }^{12}$ ). The basic questionnaire was designed on combinatory basis as having all possible focus articulations ${ }^{13}$. The obtained focus articulations were grouped as follows:

- single focal constituent

$\mathrm{SV}_{\mathbf{F}}$

$\mathrm{AOV}_{\mathbf{F}}$

$\mathbf{S}_{\mathrm{F}} \mathrm{V}$

$\mathrm{A}_{\mathrm{F}} \mathrm{OV}$

$\mathrm{AO}_{\mathrm{F}} \mathrm{V}$

Peripheral constituents
- multiple focal constituent

$$
\begin{aligned}
& \mathbf{A}_{F} O V_{F} \\
& \mathrm{AO}_{\mathbf{F}} \mathbf{V}_{\mathbf{F}} \\
& \mathbf{A}_{\mathbf{F}} \mathbf{O}_{\mathbf{F}} \mathrm{V} \\
& \mathbf{S}_{\mathbf{F}} \mathbf{V}_{\mathbf{F}} \\
& \mathbf{A}_{\mathbf{F}} \mathbf{O}_{\mathbf{F}} \mathbf{V}_{\mathbf{F}}
\end{aligned}
$$

As far as the study of contrast is concerned, different approaches were combined. Contrast has been singled out following the newest edition of FDG by Hengeveld and Mackenzie (2008). Contrast, as it can be inferred from the presentation by Hengeveld and Mackenzie (2008:99) always occurs in combination with either topic or focus as two other major pragmatic functions. The corresponding (contrastive) focus types identified by Dik (1997, 1:330-334) in his FG form the subcategories of these combinations. They are only one parameter for describing contrast in languages ("communicative point" in Dik's terminology (1997, 1:330)). The other parameter is the contrast scope which was studied in terms of contrast articulations, not unlike the 'focus articulations' of the basic questionnaire. For the study of contrast a simplified version of the questionnaire was employed which contained only the contrast articulations that involved a single constituent (either the predicate or a core argument) that would be contrastive or, if there were more than one contrastive constituent in the sentence, they had the same syntactic function (again, either that of a predicate or argument).

Since contrast does not occur as a single pragmatic function, contrastive constituents can be labeled in terms of FDG as 'Subacts' (SAs) with multiple pragmatic functions. The rough structure of the questionnaire for studying contrast is thus as follows (see the more detailed structure in the Appendix):

\title{
SAs with multiple pragmatic functions
}

\author{
Focus/Contrast \\ Replacing \\ Expanding \\ Topic/Contrast \\ Rejecting \\ Restricting \\ Selecting
}

\footnotetext{
${ }^{12}$ In the following this morpheme will be represented in the form of its preconsonantal allomorph me for the sake of simplicity of presentation.

${ }^{13}$ I borrowed this designation from Maslova (2005). However, my list of focus articulations counts not nine but ten of them because, unlike Maslova (2005), I established them on purely combinatory basis and not on the basis of some theoretical considerations. The focus articulation not found in Maslov (2005) is $\mathbf{A}_{\mathbf{F}} \mathbf{O}_{\mathbf{F}} \mathrm{V}$
} 


\title{
Combinations of SAs with multiple functions
}

\author{
Topic/Contrast + Focus/Contrast \\ Parallel \\ Rejecting + Replacing \\ Expanding (fuller form) \\ Topic/Contrast + Topic/Contrast \\ Restricting (fuller form)
}

To cover certain research goals mentioned in section 1.1 satisfactorily, the work with questionnaires was supplemented with the analysis of the available textual material.

\subsection{Methodological issues}

The examples listed in sections 2.1 to 2.6 represent, unless indicated otherwise, the most frequently obtained translations of the answers given to the questions from the basic questionnaire which were devised to trigger the corresponding focus articulations. These answers can thus be regarded as standard usage of TY as it is spoken today. Throughout this work, the examples were mainly obtained during elicitation sessions. Otherwise they are given with a reference to their source. The morphemic analysis is in all cases done by me.

The morphemes involved in marking focal status are glossed in accordance with the existing descriptive literature. This makes it easier for the reader to spot the deviant usages.

To illustrate a given focal articulation fully, the answers had to be given in full forms as well. This is not quite natural for TY, though, because the constituents carrying given information are normally omitted in it. Nevertheless, sentences carrying constituents redundant under normal circumstances are imaginable in certain contexts and can be found in the available published primary data. Apart from this consideration justifying the elicitation of full answers, care was taken to point out the differences, if there were any, between the focus patterns employed in such explicit sentences and sentences in which topical constituents were only implicit. If one of the main constituents is not present in the surface structure of a sentence, the letter indicating it in the abbreviated representation of the focus articulation under scrutiny is included in brackets. The resulting different representations are called 'configurations' (of a given focus articulation).

In order to collect the necessary data, a three months fieldwork was conducted during which native speakers of TY residing in Andryushkino, Cherski and Yakutsk (all in the Sakha Republic of the Russian Federation) were questioned. Altogether 13 informants were consulted with varying degree of thoroughness, which was mainly conditioned by the availability of the informants and the setting in which interviews took place. Four informants were male, nine female. The majority of them were over 50 years of age. The main informants were well over 60 . All informants were permanent residents of a multiethnic settlement.

Russian served as the medium language in all elicitation sessions. 


\section{SAs with the Single Pragmatic Function of Focus}

As it is mentioned in section 1.3, several pragmatic functions can be assigned to a single constituent: focus + contrast, topic + contrast etc. In this section only constituents with the sole function of focus are systematically looked at.

\subsection{Focal predicate}

This section illustrates the morpho-syntactic structure of the sentences carrying focal predicates expressed by intransitive $\left(\mathbf{S V}_{\mathbf{F}}\right)$ and transitive $\left(\mathrm{AOV}_{\mathbf{F}}\right)$ verbs.

$\mathbf{S V}_{\mathbf{F}}$

The pragmatic function of focus in (1-2d) is unambiguously marked by the verbal clitic me. The predicate is the only constituent in the answers which does not contain given information.

(1) Uo neme-le(y) wie-nu-mle?

child what-FOC do-DUR-TR.3SG.OF

'What is the child doing?'

Uo / Tudel mer=ayal'waa-nu-j.

child / 3SG PREDF=laugh.INCH-DUR-INTR.3SG

'The child / S/He is laughing.'

$\mathrm{AOV}_{\mathbf{F}}$

According to Krejnovič $(1958: 43)$ the answers with a focalized transitive verb are prompted by the questions with the structure "What did A do?". In fact such questions regularly produce answers with the pattern characteristic of sentences with the configuration $A \mathbf{O}_{\mathbf{F}} \mathbf{V}_{\mathbf{F}}$ (OF pattern) exemplified in (8a) and (8b). In order that just a focalized verb form be obtained in the answer, both $\mathrm{A}$ and $\mathrm{O}$ have to be mentioned in the question. This makes them the constituents carrying given information in the answer and thus deprives them of the status of the potentially focalizable ones.

(2a) Ieruu-če lalime-le quode-l'ii-m?

hunt-NMLZ sledge-ACC how-hold-TR.3SG

What did the hunter do with the sledge?

Ieruu-če / Tudel lalime-le / tay-n'e-le me=köjle-su-m. hunt-NMLZ/3SG sledge-ACC / DEM-COM-ACC PREDF=break-CAUS-TR.3SG

'The hunter / He broke the sledge/it.' 
(2b) Lalime tet quode-l'ii-mek?

cledge 2SG how-hold-TR.2SG

'What did you do with the sledge?'

$\begin{array}{lll}\text { Met } & \text { lalime }(\eta) & m e=k o ̈ j l e-s u-\eta \\ 1 \mathrm{SG} & \text { sledge } & \text { PREDF=break-CAUS-TR-1SG.TR }\end{array}$

'I broke the sledge.'

For the answer to the question from (2b) to be understood as it is intended according to its translation, a short pause would have to follow the personal pronoun in order that its function be disambiguated, i.e. that it be interpreted as the subject of the sentence. Otherwise it could be taken for a possessive pronoun modifying the word lalime(y), the object of the sentence, which would result in the meaning: "[I] broke my sledge". This functional disambiguation can take place in an alternative manner, by employing a marked word order as in (2c):

(2c) Lalime met me=köjle-su- $\eta$.

sledge 1SG PREDF=break-CAUS-1SG.TR

'I broke the sledge.'

The ambiguity of this kind does not arise if an independent demonstrative pronoun functions as the object:

$$
\begin{array}{lll}
\text { Met } & \text { tagi } & m e=k o ̈ j l e-s u-\eta \\
1 \mathrm{SG} & \text { DEM } & \text { PREDF=break-CAUS-1SG.TR }
\end{array}
$$

'I broke it.'

\subsection{Focal core argument}

The single focal constituent of a sentence can be represented by a core argument. With intransitive verbs it can be only $\mathrm{S}$ while transitive verbs can have either the focal subject (A) or the focal direct object (O). The morphological equipment of the focal arguments and their predicates encoded in accordance with the syntactic function of the focal arguments is shown in (3a-6b).

\section{$\mathbf{S}_{\mathbf{F}} \mathrm{V}$}

All informants over 50 years of age form the sentences with the focal $S$ in a uniform and predictable way demonstrated in (3a). The assignment of the function of focus to the subject takes place through attaching to it the nominal focus marker, the suffix -ley:
Kin-ek aral'waa-nu-l?
who-FOC laugh.INCH-DUR-NMLZ.SF
'Who is laughing?'
Uo-ley aral'waa-nu-l.
child-FOC laugh.INCH-DUR-NMLZ.SF
'A/The child is laughing.' 
In the short answer with the configuration $\mathbf{S}_{\mathbf{F}}(\mathrm{V})$ the subject is invariantly accompanied by the nominal focus marker-ley irrespective of the age of the informant:

Uo-ley.

child-FOC

'A/The child [is].'

The greater degree of uniformity in the answers with the reduced configuration of this focus articulation could be explained by the supposition that the focal marker -ley is reinterpreted by the speakers as the homonymic copula, which must not be missing in a TY sentence with a nominal predicate.

\section{$\mathbf{A}_{\mathbf{F}} \mathrm{OV}^{14}$}

In both of his major treatises of TY Krejnovič $(1952,1982)$ gives hardly any example with the full configuration of this focus articulation. However, his presentation does give an impression that a direct object can be used in the sentences with focal A occupying the position either in front of the group $\mathbf{A}_{\mathbf{F}} \mathrm{V}$ or behind it. The scarcity of available information about this focus type makes it especially interesting. Another intriguing and controversial feature of this focus articulation is the fact that in Kurilov's (2001) view its predicate is encoded in exactly the same way as is the predicate in the focus articulation $\mathbf{S}_{\mathbf{F}} \mathrm{V}$, which contradicts completely the accounts by Krejnovič $(1958,1982)$ and Kurilov (2006).

The focus articulation $\mathbf{A}_{\mathbf{F}} \mathrm{OV}$ shows the greatest variation from speaker to speaker and within single speakers. It is especially true for its full configuration. In spite of the relatively high degree of divergence, three common encoding patterns can be distinguished and certain tendencies in encoding the constituents of the sentences with this focus articulation can be observed. In discussing this matter it is reasonable to differentiate between the full configuration of this focus articulation and the reduced forms thereof: $\mathbf{A}_{\mathbf{F}}(\mathrm{O}) \mathrm{V}$ and $\mathbf{A}_{\mathbf{F}}(\mathrm{OV})$.

In the sentences with the configuration $\mathbf{A}_{\mathbf{F}}(\mathrm{O}) \mathrm{V}$ the AF pattern prevails. It is characterized by the fact that both the subject and the predicate are deprived of any inflexion, the only exception being the 3PL form of the verb that has a plural affix $-\eta u$.

(4a) Kin- Ø lalime-le köjle-s-Ø? - Ieruu-če- Ø/Met- Ø köjle-s- Ø.

who-AF sledge-ACC break-CAUS-AF hunt-NMLZ-AF/1SG-AF break-CAUS-AF

'Who broke the sledge?' - 'A/The hunter / I broke.'

With the configuration $\mathbf{A}_{\mathbf{F}}(\mathrm{OV})$, the number of the informants who encode the only overt constituent, the subject, as SF form ${ }^{15}$ rises. It is regarded as an alternative even by those informants who reject the SF form of the subject in the sentences with the configuration $\mathbf{A}_{\mathbf{F}}(\mathrm{O}) \mathrm{V}$. The employment of the nominal focus marker, characteristic of the SF pattern and unexpected in (4b), can probably be explained by the same logic as in (3b).

\footnotetext{
${ }^{14}$ The word order in this symbolic abbreviation reflects the unmarked word order in the majority of sentence types with a verbal predicate in TY. Being an abstract symbol, it should not be taken as the actual or sole word order in the sentences with this particular focus articulation.

${ }^{15}$ Notably, this happens, if at all, only if the subject is not $3 \mathrm{SG}$.
} 
(4b) Kin lalime-le köjle-s- Ø? - Met-ek.

who sledge-ACC break-CAUS-AF 1SG-FOC

'Who broke the sledge?' - 'I [did].'

In the full configuration, the expected $\mathrm{AF}$ pattern is sometimes replaced by the $\mathrm{BC}$ ("basic conjugation', see 2.3) form of the verb. For this reason the form of the subject in such sentences, though formally identical with that of the subjects in the sentences formally encoded as having $\mathrm{AF}$, cannot be called AF form any longer.

(4c) Kin-ek lalime-le köjle-su-m?

who-FOC sledge-ACC break-CAUS-TR.3SG

Ieruu-če lalime-le köjle-su-m.

hunt-NMLZ sledge-ACC break-CAUS-TR.3SG

'Who broke the sledge?' - 'A/The hunter broke the sledge.'

Two out of 10 consulted informants employ the of pattern with the full configuration.

(4d) Kin-ek lalime-le salyarej-m? - Met lalime-le salyarej-mey. who-FOC sledge-ACC break-TR.3sG hunt-NMLZ sledge-FOC break-TR.1/2sG.OF

'Who broke the sledge?' - 'I broke the sledge.'

Possible reasons for the deviant patterns in (4c) and (4d) are suggested in section 2.7.

From Kurilov's remarks (personal communication) it follows that there are basically two strategies of encoding the focus articulation $\mathbf{A}_{\mathbf{F}} \mathrm{OV}$ : the basic form of the subject is accompanied by the AF or SF verb form. The former is normally employed in utterances in which the object is not expressed like in (4a). The latter, known from KY, can occur also in sentences containing a direct object. Note the absence of the focus marker on the subject ${ }^{16}$ :

\section{(5a) Laame čuule lew-l. \\ čuul-le \\ dog meat-ACC eat-NMLZ.SF \\ '[It is] the dog [that] has eaten the meat.'}

While the subject and the object in (5a) can switch places, the former strategy of expressing AF in sentences with an overt object is associated with the fixed marked word order OAV:

(5b) Čuule laame lew- $\varnothing$.

meat.ACC dog eat-AF

'[It is] the dog [that] has eaten the meat.'

According to Kurilov (personal communication), (5b) is more categorical: "the dog and no-one else".

(5a) represents a mixed syntactic structure as the morphological equipments of the predicate and the subject are not congruous: the predicate is encoded as focalizing $S$ while the subject

\footnotetext{
${ }^{16}$ Kurilov admitted, however, that, though less frequently, the focus marker can be attached to the subject
} 
lacks the focal ending characteristic of S-arguments. The mix-up can have the opposite constellation as in $5 \mathrm{c}$ where the focal ending - ek of the question word that normally should occur in sentences with the SF verb form is accompanied by the AF form of the verb.
(5c) Tet kewej-qane kin-ek endii-t- $\varnothing \quad$ titte-yane?
2SG leave-LOC who-FOC keep.alive-FUT-AF 3PL-ACC
'Who will support them if you leave?'

Kurilov (2001:598)

With ditransitive verbs, only the strategy in (5a) appears to be possible:

(5d) Uraritče tetrad'-le uoy-in tadi-l.

teacher copybook-ACC child-DAT give-NMLZ.SF

'[It is] the teacher [who] gave the copybook to the pupil.'

\section{$\mathrm{A} \mathbf{O}_{\mathrm{F}} \mathrm{V}$}

All but one elderly speaker encode this focus articulation in the same way, fully conformant with the previous descriptions.

(6a) Ieruu-če neme-le(y) köjle-s-mele?

hunt-NMLZ what-FOC break-CAUS-TR.3SG.OF

'What did the hunter break?'

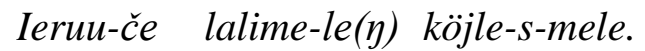

hunt-NMLZ sledge-FOC break-CAUS-TR.3SG.OF

'The hunter broke a sledge.'

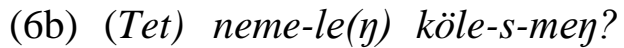

(2SG) what-FOC break-CAUS-TR.1/2SG.OF

'What did you break?'

(Met) lalime-ley kojle-s-mey.

(2SG) sledge-FOC break-CAUS-TR.1/2SG.OF

'I broke a sledge.'

The younger speakers have different deviations from this pattern.

\subsection{Focal peripheral constituent}

When a sentence contains a focal peripheral constituent, it is regularly accompanied by the omission $^{17}$ of the verbal focus marker, the clitic me, but no special marker is employed. The verbal endings in the answers are those of BC. Thus, this focus articulation is marked negatively

\footnotetext{
${ }^{17}$ Some informants consider such an omission facultative when asked specifically about the possibility of retention of the clitic but never fail to omit $m e$ in spontaneous utterances with focal peripheral constituents. See however section 4 for the usage of cliticized verbs in sentences with focal peripheral constituents and the explanation of that phenomenon.
} 
in affirmative sentences ${ }^{18}$, as far as the morphological means are concerned. A few examples follow to illustrate that.

- oblique cases

(7a) Tet wadu-n nime qadaa ögetej-mek?

2SG Yukaghir-RLN house where put-TR.2SG

'Where did you put the tent?'

Met wadu-n nime Čamuol-el Uluro ajaduol'-da-ya ögetej- $\eta$.

1SG Yukaghir-RLN house be.big-NMLZ Uluro shore-POSS-LOC put-1SG.TR

'I put it at the shore of Big Uluro.'

- adverbials

(7b) Lasu qanin kewej? - Lasu awjaa keweč.

kewej- $\varnothing$

Lasu when leave-3SG.ITRG Lasu yesterday leave.INTR.3SG

'When did Lasu leave?' - 'Lasu left yesterday.'

A comparison of the message conveyed in $(7 \mathrm{c})$ and $(7 \mathrm{~d})$ is very illustrative too.

(7c) Malaa tet čii quodey sarane-l-pe-gi n'ied'i-k! -

INCT 2SG people how sit-NMLZ-PL-POSS tell-IMP.2SG

'Well then, tell [me] how your parents are doing!'

Met čii amutney sayane-yi.

1 SG people be.good.ADV sit-3PL.INTR

(Tittel) $M e=\check{c} a \gamma a d ' a a-n u-\eta i$.

(3PL) PREDF=work.INCH-DUR-3PL.INTR

'My parents are doing well. They continue to work.'

The presence of a modal adverb accounts predictably (see Krejnovič 1958:151) for the lack of the verbal focal clitic $m e$ in the first sentence of the answer. Just as logical is the presence of that clitic in the last line of (7c), represented by the verb-only sentence in which the predicate carries the new relevant information. But this changes if a focal peripheral constituent is added which is marked by its preverbal position in the sentence and the intonation:

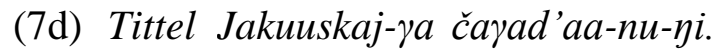

3PL Yakutsk-LOC work.INCH-DUR-3PL.INTR

'They continue to work in Yakutsk.'

This pattern was recognized by Comrie (1992) who proposed the label 'neutral focus' for it because he regarded the corresponding forms as basic. Since the word 'focus' very generally implies concentration of attention on something, the term 'neutral' can hardly be applied here.

\footnotetext{
${ }^{18}$ There is a special interrogative paradigm for questions to peripheral constituents (Maslova 2003c:20)
} 
Neither can the designation 'unmarked indicative', proposed by Fortescue (1996:21) be adequate for these verb forms. First of all, they are, contrary to what Fortescue (1996) believed having analyzed Krejnovič's $(1958,1982)$ material, not confined to the indicative mood s.s. Second of all, verb forms as in $7 \mathrm{~d}$ serve to express the narrow focus on a peripheral constituent and are in such contexts anything else but functionally unmarked. However, they seem to represent a 'default' option in certain other contexts (e.g. the use of the BC form in APSs, see 3.1) To my mind, it is therefore more preferable to designate the verb form of the predicate in $7 \mathrm{~d}$ simply as the 'basic conjugation' form, or, abbreviated, the $\mathrm{BC}$ form of the verb.

Focus is the main communicative point to be conveyed by the speaker to the listener. The constituent(s) effecting such transfer of information is/are called focal. Focal constituents are encoded, or focalized, in TY with morphological means. Since morphological markers of TY have complementary distribution, only one constituent in a given sentence can be actually focalized morphologically. So far only cases with a single focal constituent have been dealt with. Therefore, it is interesting to find out now which of the multiple focal constituents receives the corresponding morphological marking. This is done in sections 2.4 to 2.6 that follow.

\subsection{Topical argument}

\section{$\mathrm{AO}_{\mathbf{F}} \mathbf{V}_{\mathbf{F}}$}

The absolute majority of the informants encode this focus articulation employing the of pattern:

(8a) Ieruu-če neme-ley wie-mele?

hunt-NMLZ what-FOC do-TR.3SG.OF

'What did the hunter do?'

Ieruu-če lalime-ley köjle-s-mele.

hunt-NMLZ sledge-FOC break-CAUS-TR.3SG.OF

'The hunter broke a/the sledge.'

(8b) Tet neme-le wie-men?

$2 \mathrm{SG}$ what-FOC do-TR.1/2SG.OF

'What did you do?'

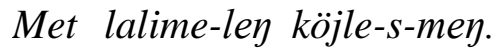

$1 \mathrm{SG}$ sledge-FOC break-CAUS-TR.1/2SG.OF

'I broke a/the sledge.'

This quite regular pattern is just as regularly broken if the sentence pair is designed in a certain way:

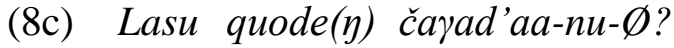

Lasu how work.INCH-DUR-3SG.ITRG

'How does Lasu work?' 
Tude wie-l-moraw-rane me=wie-nunu-m.

3SG do-NMLZ-OBL-ACC PREDF=do-HAB-TR.3SG

'[He] fulfills his tasks.'

One's tasks equal one's work, therefore it does not surprise that the word wielmorawyane is degraded in the answer in its focal status. It simply is not new. It actually carries implicitly given information despite not having been explicitly mentioned in the question. Instead the speaker concentrates his attention and the attention of the inquirer on the predicate whose content cannot be foreseen by the latter, thus PREDF.

\section{$\mathbf{A}_{\mathbf{F}} \mathrm{OV}$ F}

This focus articulation is not covered in Maslova (2005) and the following description is thus an attempt to close this gap. Considering the high degree of divergence attested for the focus articulation $\mathbf{A}_{\mathbf{F}} \mathrm{OV}$, it is not surprising that this focus articulation shows varying patterns of encoding, sometimes even in one speaker. To illustrate it, a few examples are quoted:

(9a) Ieruu-če quode gurčii- $\emptyset$ ?

hunt-NMLZ how become-3sG.ITRG

'What has happened to the hunter?'

Tude-yale qajčie-tege uu-se-

3SG-ACC grandfather-AUG go-CAUS-AF/-TR.3SG.OF/-TR.3SG

'A bear attacked him.'

"A big grandfather touched/disturbed him (lit. "made him go")."

The interpretation of the alternative verb forms in the answer is additionally made harder by the informant's claim that neither of them emphasizes a constituent, but all of them rather just state a fact. It is conspicuous that in spite of the indifference of this particular informant she does not use the PREDF form of the verb in this context. When the configuration is reduced to $\mathbf{A}_{\mathbf{F}}(\mathrm{O}) \mathbf{V}_{\mathbf{F}}$, the OF form of the verb, naturally, does not occur any longer but both others do. The PREDF form of the verb does occur when the subject of the sentences with such reduced configuration is a pronominal one, especially when it is omitted. The latter is probably the reflection of the normally obligatory usage of the clitic $m e$ in verb-only sentences:

$$
\begin{aligned}
& \text { Quode gurčii- } \emptyset \quad \text { ilwii-če? } \\
& \text { how become-3sG.ITRG graze-NMLZ } \\
& \text { 'What her } \text { (1SG) PREDF=riteprimand-1SG.TR } \\
& \text { 'Whappened to the herdsman?' - '(I) reprimanded [him]'. }
\end{aligned}
$$

Some other speakers are more liberal with the usage of me attaching it also to predicates with nominal subjects.

A specific attested usage is represented by application of exclusively $\mathrm{BC}$ form of the predicate for this focus articulation, which could be a sign of deterioration of the focus system. In a more competent speaker this usage is spontaneous as long as the subject is nominal. Here it might be an expression of a compromise in a conflicting situation. 
Some elderly speakers are very clear about the usage of the verb forms in the two following alternative answers with reduced configuration to the question "What has happened to the teacher?", (9c) stressing the subject and (9d) emphasizing the action.
(9c) Met- $\varnothing$ l'iteges- $\emptyset$.
$1 \mathrm{SG}-\mathrm{AF}$ beat-AF
(9d) $M e=$ '’itegesu- $\eta$.
PREDF=beat-1SG.TR
'I have beaten [him] up.'
'[I] have beaten [him] up.'

This confirms that there is a high degree of confidence in the competent speakers regarding the choice of the focal pattern when redundant constituents, here $\mathrm{O}$, are absent. It is only natural that no informant with the exception of two ${ }^{19}$ uses the OF form of the verb with the focus articulation $\mathbf{A}_{\mathbf{F}} \mathrm{OV}$.

The occurrence of the AF focus pattern in the focus configuration $\mathbf{A}_{\mathbf{F}} \mathrm{OV}_{\mathbf{F}}$ as exemplified in (9c) corrects Maslova's (2005:606) claim that "the AF construction ... marks the remainder of the clause ... as its pragmatic supposition and is available only if $q(x, \mathrm{O})$ can be assumed to be known by the listener(s)". That the AF construction, contrary to what Maslova (2005:607) concludes, need not encode "only narrow focus on A", is confirmed also elsewhere. The following sentence pair is taken from a story in which a glutton approaches different entities trying to find out who is the strongest one. In (9e) it asks this question of a cloud.

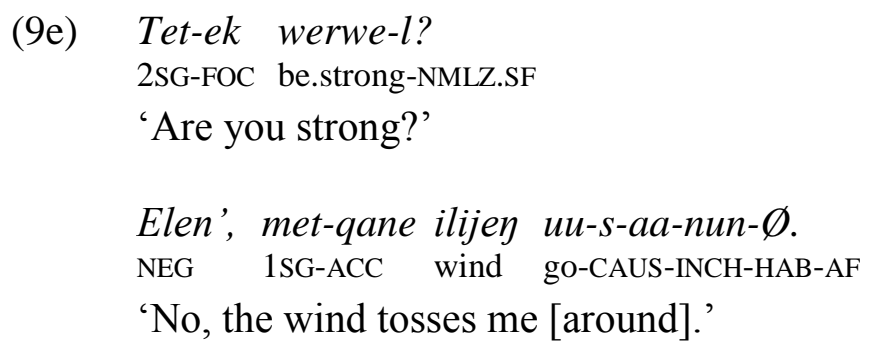

(Kurilov 2005:242)

The same story contains an instance of this focus articulation being encoded as having predicate focus, which very clearly shows that both patterns are equally possible:

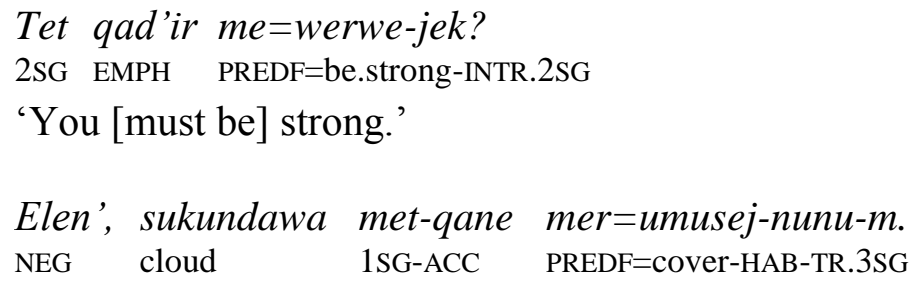

(Kurilov 2005:242)

\footnotetext{
${ }^{19}$ For one of them it does not seem to have its focal function and the other did it with the subject in 1sG. In the paradigm of verbal endings of this latter consultant, however, the corresponding ending -mey seems to express PREDF sometimes.
} 
The choice of the particular focus construction in (9e) and (9f) is most probably dictated by the focus construction employed in the questions: the subject and the predicate are focalized respectively. Normally the same focus construction is used in the anticipated form of an answer to a question. Besides, the subject and the predicate in the answers in (9e) and (9f) are used contrastively with respect to their counterparts in the questions, which naturally triggers the corresponding focus constructions.

In some situations, even if the answer is not given in the anticipated form, certain choices seem to be favored. The absolute majority of the informants answer the question in $(9 \mathrm{~g})$ with the PREDF verb form:

(9g) Lasu quode čarad'aa-nu- Ø?
Lasu how work.INCH-DUR-3sG

'How does Lasu work?'

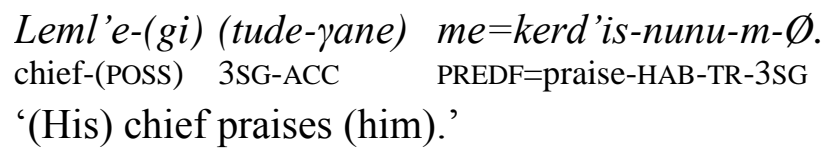

No one forms this sentence with AF. This is not surprising in the given context because once the speaker has chosen this somewhat unusual form of the answer judging Lasu's work by how much he is praised for it by others, it is the chief whose opinion and attitude is most important. The chief is therefore is an expected participant of the state of affairs described in the sentence, or an inferred topic, whereas his opinion cannot be foreseen by the listener, thus the emphasis on the predicate.

In the second sentence of (9h) all but one informant put the predicate in its $\mathrm{BC}$ form, the "stray" variant being PREDF, impossible by a judgment. It is claimed (Kurilov, personal communication) that the subject is emphasized in the speaker B's utterance.

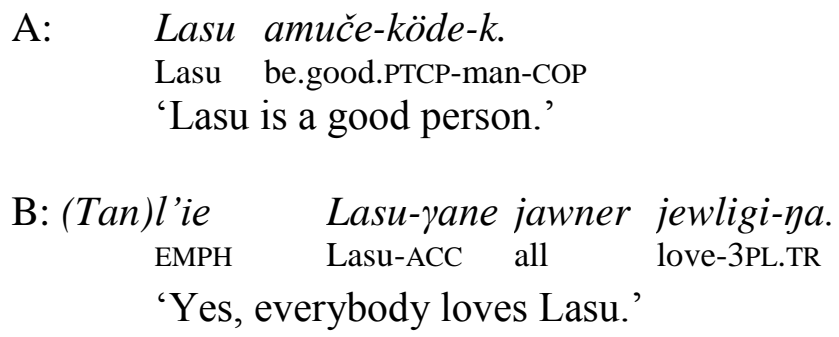

While the second speaker's choice of the particular verbal lexeme in this short dialogue cannot be foreseen by the first speaker, it is not really something conceptually new to the latter if the second speaker agrees with him in assessing Lasu's personality. Since the second speaker's opinion does coincide with that of the first one, the second speaker does not consider it necessary to focalize the predicate. On the other hand, it is quite reasonable to stress that literally everybody likes Lasu. The subject is, in such a case, emphasized here by syntactic means only (immediate preverbal position), the morphological AF marking lacking altogether. It seems to be a property of the pronoun jawner that it carries the focus of the utterance by default and the predicate need not be in the AF form.

Unfortunately, clear generalizations can hardly be made with respect to the full configuration of this focus articulation. With the reduced articulation lacking an explicit object, which is more 
frequent in natural speech, the choice of either AF or PREDF verb form in competent speakers depends predictably on which of the constituents they wish to emphasize.

\subsection{Topical predicate}

\section{$\mathrm{A}_{\mathrm{F}} \mathrm{O}_{\mathrm{F}} \mathrm{V}$}

The absolute majority of the informants chose of while encoding this focus articulation.

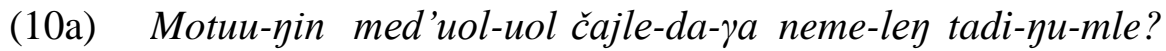

Motuu-DAT be.born-PASS day-POSS-LOC what-FOC give-PL-TR.3PL.OF

'What did one give Motuu for her birthday?'

Lasu tud-in moyo-le tadi-mle.

Lasu 3SG-DAT hat-FOC give-TR.3SG.OF

'Lasu gave her a hat.'

(10b) Met tud-in moyo-ley tadi-mey.

1SG 3SG-DAT hat-FOC give-TR.1/2SG.OF

'I gave her a hat.'

It appears that the object has a priority of being formally assigned the focal status in the focal pairs $\mathbf{A}_{\mathbf{F}} \mathbf{O}_{\mathbf{F}}$ and $\mathbf{O}_{\mathbf{F}} \mathbf{V}_{\mathbf{F}}$.

\subsection{Thetic sentences}

\section{$\mathbf{S}_{\mathbf{F}} \mathbf{V}_{\mathbf{F}}$}

This focus articulation was studied in two types of dialogue. In the first dialogue (11a) a rather extraordinary or unexpected event is reported in an excited manner. In the second dialogue (11b) the events that are probably expected or at least natural and in no way extraordinary, are reported in a peaceful manner.

While the majority of elder informants apply PF with this focus articulation, the younger speakers show the tendency to drop the clitic $m e$, which transforms the verb form into BC.

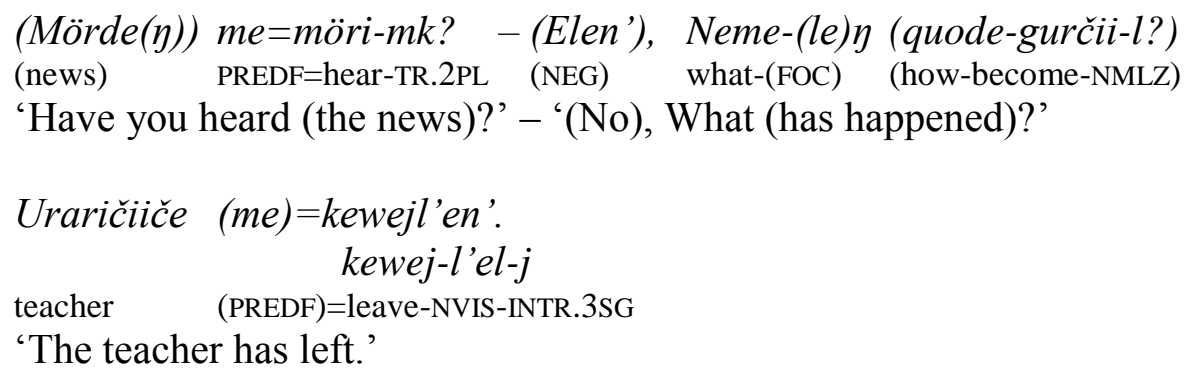

In the dialog of the second type the speakers show much more uniformity encoding the nonmodified predicates as PREDF: 
(11b)
Neme-le(y) ni'ed'i-te-mk? -
what-FOC tell-FUT-TR.2PL
'What's new?'
Tan l'ie, met paad'eduo köde-yin' uu-j ${ }^{20}$ tadaat me=keweč,
and EMPH 1SG daughter man-DAT go-INTR.3SG then PREDF=leave.INTR.3SG

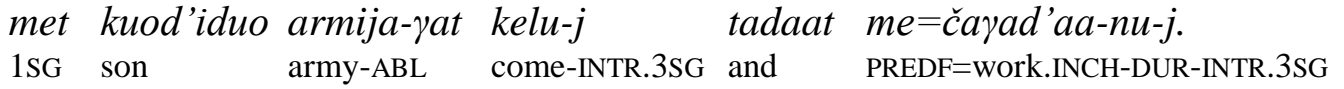
Met könme eguojie köl-te-j. Jawner mer=amuč.
$1 \mathrm{SG}$ wife tomorrow come-FUT-INTR.3SG everything PREDF=be.good.INTR.3SG

'Well, my daughter married and went away; my son came back from the army and works [now]. My wife is coming tomorrow. Everything is all right.'

These findings seem to contradict Maslova's (2005:605) observations about thetic sentences involving intransitive verbs, namely that "the SF construction subsumes both ... S-focus and sentence focus". This, however, is only an apparent contradiction because in all three examples that Maslova (2005) gives in order to substantiate her claim the S-argument fulfills not only the function of focus but also that of the topic thus being a part of a presentative sentence which behave differently from the categorical sentences regarding the encoding strategies of the pragmatic function of focus. Presentative sentences are discussed in section 3.1. If the Sargument of a thetic sentence is only assigned the function of focus, in the vast majority of cases the sentence is encoded as having PREDF and not SF.

Notwithstanding the above-mentioned, in the dialogues of both types one informant respectively prefers an SF verb form:

\section{(11c) Met mirije eguojie kelu-te-l. \\ 1SG wife tomorrow come-FUT-NMLZ.SF \\ 'My wife is coming tomorrow.'}

This deviation from the common encoding choice shows that the choice becomes relatively free once a discourse goes beyond simple question-answer constellation. In the particular context of the second dialogue the SF choice is logical in a sense. The verb "come" had become topical by the time the speaker reached the point at which he uttered the sentence in (11c). He had been speaking about his son's coming back from the army and now it is his wife who is coming. So, notwithstanding the fact that there is often a preferred focal encoding pattern, depending on the speaker's perspective and provided that the context allows it, alternative encoding patterns can be chosen, as could be expected of a living language.

\footnotetext{
${ }^{20}$ It is not quite natural for TY to have more than one finite verb in the same sentence, unless the verbs express alternative actions. This translation must be a replica of the Russian sentence. Normally, a TY speaker would attach the personal endings only to the last verb in a sentence encoding all other verbs as converbs. Note the lack of the clitic me with the verb forms uuj, keluj and költej. Both verbs are modified unlike their counterparts with the focal clitic.
} 


\section{$\mathbf{A}_{\mathrm{F}} \mathbf{O}_{\mathrm{F}} \mathbf{V}_{\mathrm{F}}$}

This focus articulation was studied in the same types of dialogues as the preceding one. For the first type of dialogue the translations could be obtained only from 5 informants and thus can hardly have any statistical value. But even those few translations again indicate how much variation in the encoding of the predicate there is when $\mathrm{A}$ is a focal constituent. Three informants choose $\mathrm{BC}$, one - OF, and yet another one uses AF to encode the predicate of the affirmative sentence conveying the new information. The more common choice, the $\mathrm{BC}$, is exemplified here:

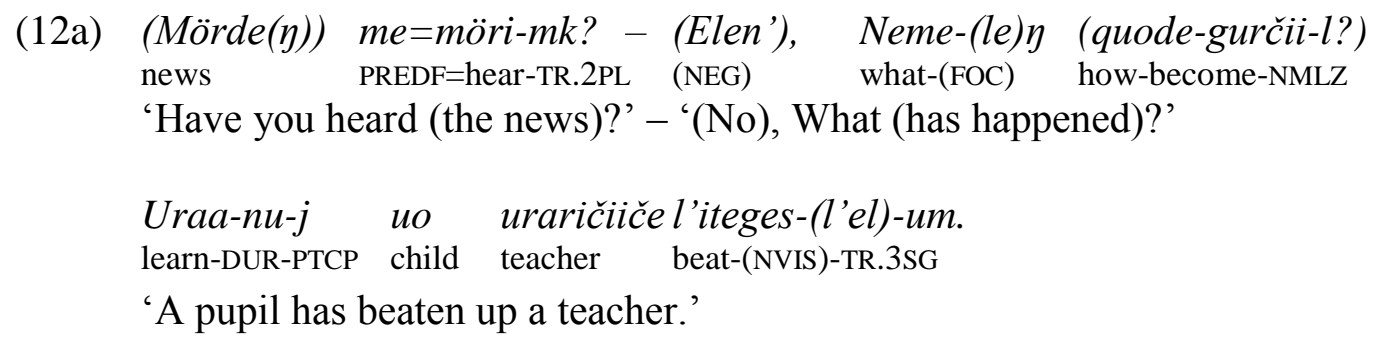

'A pupil has beaten up a teacher.'

The picture is not less colorful in the second type of dialogue. However, the encoding of the predicate(s) as PREDF prevails numerically and is observed in speakers of different ages. The encoding pattern CVB+PREDF (see footnote 20) is employed here to illustrate this focus articulation:

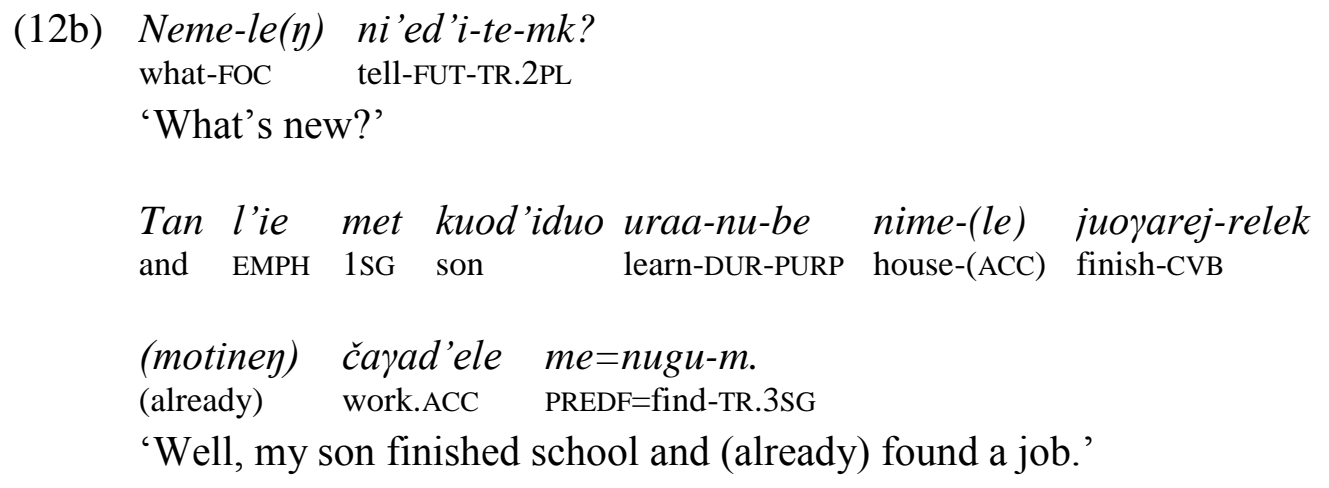

'Well, my son finished school and (already) found a job.'

It should be noted that despite of a clear tendency to prefer PREDF verb forms some speakers employed other encoding patterns which are presented below for the sake of completeness. These can be divided in two groups: both predicates are represented by finite verbs vs. only the last predicate is finite. The informants' choices are then as follows:

$$
\begin{array}{ll}
1^{\text {st }} \text { group } & 2^{\text {nd }} \text { group } \\
\text { BC+BC (2 speakers) } & \text { CVB+PREDF (2 speakers) } \\
\text { PREDF+PREDF (2 speakers) } & \text { CVB+OF (1 speaker) } \\
\text { OF+OF (1 speaker) } &
\end{array}
$$

This is in clear disagreement with Maslova's (2005:606) generalization that this focus articulation is subsumed under the of construction. 
The $\mathbf{A}_{\mathbf{F}} \mathbf{O}_{\mathbf{F}} \mathbf{V}_{\mathbf{F}}$ focus articulation obtains also when a sensible answer simply does not contain any constituent of the question. With the following question-answer pair elderly informants construct the answer with the OF form of the verb and the younger ones - with its BC form.

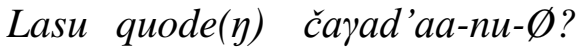
Lasu how work.INCH-DUR-3SG.ITRG
'How does Lasu work?'
Leml'e wien čii-k kerd'i-s-nun-mele.
boss other people-FOC boast-CAUS-HAB-TR.3SG.OF
'The boss praises others.'

This answer obviously carries contrastive meaning. Since it is the object that is contrastively used, the occurrence of the OF verb form in this somewhat unusual answer is but natural. This sentence is an indication that focus and contrast are expressed by the same morphological means in TY.

\subsection{Focus articulations of TY: generalizing remarks}

On the basis of the examples in sections 2.1 to 2.6 an overview of the focus system of TY can be given:

- single focal element

$S V_{F}>$ PREDF

$\mathrm{AOV}_{\mathbf{F}}>\mathrm{PREDF}$

$\mathbf{S}_{\mathrm{F}} \mathrm{V}>\mathrm{SF}$

$\mathbf{A}_{\mathbf{F}} \mathrm{OV}>$ divergent

$\mathrm{AO}_{\mathbf{F}} \mathrm{V}>$ mainly $\mathrm{OF}$

Peripheral constituents $>$ BC
- multiple focal elements

$\mathbf{A}_{\mathbf{F}} \mathrm{OV}_{\mathbf{F}}>$ divergent

$\mathrm{AO}_{\mathbf{F}} \mathbf{V}_{\mathbf{F}}>\mathrm{OF}$

$\mathbf{A}_{\mathbf{F}} \mathbf{O}_{\mathbf{F}} \mathrm{V}>\mathrm{OF}$

$\mathbf{S}_{\mathbf{F}} \mathbf{V}_{\mathbf{F}}>$ mainly PREDF ${ }^{21}$

$\mathbf{A}_{\mathbf{F}} \mathbf{O}_{\mathbf{F}} \mathbf{V}_{\mathbf{F}}>$ tendentially PREDF

Ultimately, it is the particular context of the state of affaires described that decides over the speaker's choice of a focal pattern as has clearly been shown in (8c), (9g), (11c) and (12c).

Several hierarchies for focalizing a constituent in sentences with multiple focal constituents can be established. (7d) and (11b) suggest that a peripheral constituent carrying new information is perceived by the speakers as more salient than a predicate with the same information structure, which results in the $\mathrm{BC}$ form of the predicate, thus: $\mathrm{X}_{\mathrm{F}}>\mathrm{V}_{\mathrm{INTRF}}$, where $\mathrm{X}$ represents the peripheral constituent. There is only one comparable example with a sentence containing a transitive verb in my material but it clearly indicates that the opposition transitive/intransitive is irrelevant. In no single elicitation of it do informants use PREDF form of the verb, which makes it possible to state the hierarchy more generally as $\mathrm{X}_{\mathrm{F}}>\mathrm{V}_{\mathrm{F}}$. It must be admitted, however, that the matter is additionally complicated here by the presence of a direct object which also ranks rather high in the focal hierarchy. The choice of the particular focus pattern in sentences with a transitive verb goes hand in hand with the placement of the focal direct object or the focal peripheral constituent in the immediate preverbal position, a privileged position for assigning the function of focus. If the object stands in it, the sentence is encoded as having OF, if that slot is occupied by a

\footnotetext{
${ }^{21}$ This holds unless there is a focal peripheral constituent, then BC.
} 
peripheral constituent, the $\mathrm{BC}$ form of the verb is chosen assigning the focus function to that peripheral constituent. It is one of the clearest proves of the influence of the syntax in the domain of pragmatics in TY, a language which is famous for its morphologically marked focus.

The other two hierarchies are as follows:

- in non-thetic sentences: $\mathrm{O}_{\mathrm{F}}>\mathrm{A}_{\mathrm{F}} / \mathrm{V}_{\mathrm{F}}$

- in thetic sentences: $V_{F}>S_{F}$ and less consistent but tendentially $V_{F}>A_{F} / O_{F}$

The above-mentioned observations allow to equate in non-thetic sentences the direct object with the peripheral constituent with respect to their rank in the focal hierarchy: $\mathrm{O}_{\mathrm{F}}=\mathrm{X}_{\mathrm{F}}$.

It is apparent that among the speakers of TY there is a substantial degree of variation in encoding different focus articulations. As could be expected from an endangered language, the speakers pertaining to the older generation, on the whole, show more conformity with the previous descriptions of TY in employing focal patterns. The deviant usages in some of the younger speakers can definitely be taken as signs of the deterioration of the focus system in TY. For instance, the youngest informant consulted does not use the morphological patterns of SF, AF and $\mathrm{OF}^{22}$ switching only from $\mathrm{BC}$ to PREDF. Another informant used the verbal endings of AF, oF and $\mathrm{BC}$ interchangeably denying their emphatic value. Some informants provide translations that are contradictory not only to the existing descriptions of TY focus system but to their own comparable translations made on other occasions, which is indicative of the focus system being unstable in them (see also section 9.1). On the other hand, there seem to be instances of deviant usages that are of a more systematic nature. One good example of this is the use of the BC form of a transitive verb to stress the object of the sentence as long as the subject is $3^{\text {rd }}$ person (see section 9.2). In this latter case one probably cannot speak of the deterioration of the focus system but should consider those deviations as (systematic) modifications of that system, whatever their origin may be. Thus, alternative focus subsystems would have to be recognized for TY.

The least divergences are observed in the sentences involving a predicate expressed by an intransitive verb. In the sentences with transitive verbs the stability of the focal patterns is mostly maintained as long as $\mathrm{A}$ is not among the focal constituents. Out of 4 focus articulations involving a focal $\mathrm{A}$ only one, $\mathbf{A}_{\mathbf{F}} \mathbf{O}_{\mathbf{F}} \mathrm{V}$, is stable. While the divergence in encoding focus in the focus articulations $\mathbf{A}_{\mathbf{F}} \mathbf{O}_{\mathbf{F}} \mathbf{V}_{\mathbf{F}}$ and $\mathbf{A}_{\mathbf{F}} \mathrm{OV} \mathbf{V}_{\mathbf{F}}$ is more or less natural ${ }^{23}$, its presence in $\mathbf{A}_{\mathbf{F}} \mathrm{OV}$ calls for an explanation. The instability of the focal patterns in the sentences containing a focal A could be explained by two reasons. Firstly, this type of focus is very rarely attested in the textual material of TY. If the same holds true for the spoken language, it simply can be the first victim of the deterioration of the focus system in TY speakers, whose traces are observable in younger speakers.

The other reason is a possible interfering influence of the topical constituents ${ }^{24}$ that are normally omitted in speech (see also Kurilov 2006:267-268), since they are readily retrievable from the context, but are present in the constructed examples of this work. ${ }^{25}$ What appears in the

\footnotetext{
${ }^{22}$ She does not use them even in questions with the question word playing the role of the subject and direct object respectively.

${ }^{23}$ The degree of divergence in encoding a focus articulation generally increases together with the number of the focal constituents in it. This is logical and self-explanatory.

${ }^{24}$ As already has been noted, the sentences with the configuration $\mathbf{A}_{\mathbf{F}}(\mathrm{O}) \mathrm{V}$ are more consistent in encoding AF.

${ }^{25}$ The elicitation of the sentences having full configuration of a given focus articulation was necessary because such sentences can naturally occur in the speech flow, particularly when no constituent can be regarded as given but the
} 
sentence, are the focal constituents and when, normally suppressed, topical constituents also turn up in the surface structure of a sentence, it leads to a cognitive clash in some speakers who apparently cannot interpret and treat them as topics any longer and sometimes assign the focal status to them, which is reflected in a corresponding encoding pattern. Thus, for instance, the most natural answer to the question triggering the focus articulation $\mathrm{AOV}_{\mathbf{F}}-$ and it was the spontaneous answer with the majority of informants - is a verb-only clause. When an informant is prompted to give an answer with an overt object, it probably produces in him or her a signal that the object, since it is present, might be the constituent to be stressed. This leads to a reinterpretation of the answer as having focus on the object with the subsequent attachment of the OF verbal endings to the predicate. The fact that the answer is not an immediate reaction to a question any longer but rather a translation, being thus perceived as somewhat detached from the question, additionally induces such a reinterpretation. A similar effect is manifested in (4d) where the redundant direct object must cause the choice of the of pattern. This is, in fact, harmonious with the overall tendency that the object is preferred over the other focal constituents in being focalized.

One may object that a comparable reinterpretation and its consequences do not take place in the answers in which the object is missing but the subject is present, i.e. $A(O) \mathbf{V}_{\mathbf{F}}$. This possibly has to do with the status of the predicate in the sentences with AF. While predicates that display PREDF and OF forms can be called true predicates as having full-fledged inflexional paradigms and lacking nominal properties whatsoever, predicates representing AF that are, with the exception of 3PL, zero-ending forms, resemble possessa of possessive NPs (see Krejnovič 1958:134) and express secondary features of the focalized subjects. This led Krejnovič (1958:133) to call them "non-predicative form of the verb" and later group them together with SF predicates under the label "rank II predicates" (Krejnovič 1982:204) characterized, among other things, by the fact that they cannot occur on their own.

This is to show how PREDF and OF predicates are cognitively perceived as more similar to each other than in comparison to AF predicates. If the constituents, here predicates showing $\mathrm{AF}$ and $\mathrm{OF}$, are not readily comparable, their arguments, the subject associated with a predicate encoded as the AF form and the direct object associated with a predicate encoded as OF are not comparable either. Therefore the occurrence of $\mathrm{A}$ in the surface structure of a sentence does not produce the same effect as the occurrence of $\mathrm{O}$. Indeed, when both $\mathrm{A}$ and $\mathrm{O}$, or both candidates for an alternative potential focus assignment, are there in the answer, the only alternative assignment of the focus function that can occur in the context of the focus articulation $\mathrm{AOV}_{\mathbf{F}}$ is the one signaling the presence of $\mathrm{OF}$, never $\mathrm{AF}$.

\section{SAs with Multiple Pragmatic Functions}

Almost all focal constituents in the examples in sections 2.1 to 2.6 had only this one pragmatic function. In this section the encoding of a combination of two pragmatic functions will be presented: focal topics (3.1) as well as the combinations Focus/Contrast and Topic/Contrast (both 3.2).

speaker does not treat the utteranse as a thetic sentence but deliberatly gives focal prominence to one of its constituents treating the other (ones) as Background. 


\subsection{Focal topics (presentative sentences)}

The combination of focus and topic obtains in so called presentative sentences meant to introduce a new topic (Hengeveld and Mackenzie 2008:99).

When discussing presentative sentences in TY, it is reasonable to divide them into two groups: absolute presentative sentences (APS) which initiate a text being thus (normally) free from any preexisting context and relative presentative sentences (RPS) which introduce a new topic into an already existing context within a text.

As for the RPSs, in the overwhelming majority of them the new topic is encoded as SF form which is expected for obvious reasons:

(13a) N'aačin' čamuod'e ibal-ek l'e-l.
$\begin{gathered}\text { ćamuol-je } \\ \text { opposite be.big-PTCP mountain-Foc } \\ \text { 'Opposite there was a big hill.' }\end{gathered}$

(Krejnovič 1982:273)

In very rare instances the predicate of a sentence carrying a new topic appears in its $\mathrm{BC}$ form and the noun representing the new topic, correspondingly, in its basic form, without the nominal focus marker:

\section{(13b) Taynigine čii-n l'uore-l l'ie-nun-i. then people-PLN play-NMLZ be.INCH-HAB-INTR.3SG \\ 'In those times there used to be a festival.'}

(Krejnovič 1958:259)

In fact, the sentence in (13b) was the only example of this encoding strategy in the longest available text in TY. Since the encoding of focal topics in RPSs is otherwise very regular, one could presume that in (13b) another constituent is actually focalized. The morphological equipment of the constituents indicates that it is a peripheral constituent ${ }^{26}$, the word tannigine. But with this interpretation the sentence could not be regarded as presentative, which it undoubtedly is. Therefore an alternative explanation for the use of the $\mathrm{BC}$ form of the verb in this exceptional example should be sought.

Further instances of BC verb forms encoding focal topics in RPSs could be detected. Consider the beginning of a children story:

(13c) Kin wal'be saa tuduruun miraa-l'el-ni.

two friend forest inside walk.INCH-NVIS-3PL.INTR

'Two friends were walking in a forest.'

\footnotetext{
${ }^{26}$ This is in accordance with the earlier observed overall tendency to give preference to focalizing peripheral constituents rather then other potentially focal constituents in TY.
} 


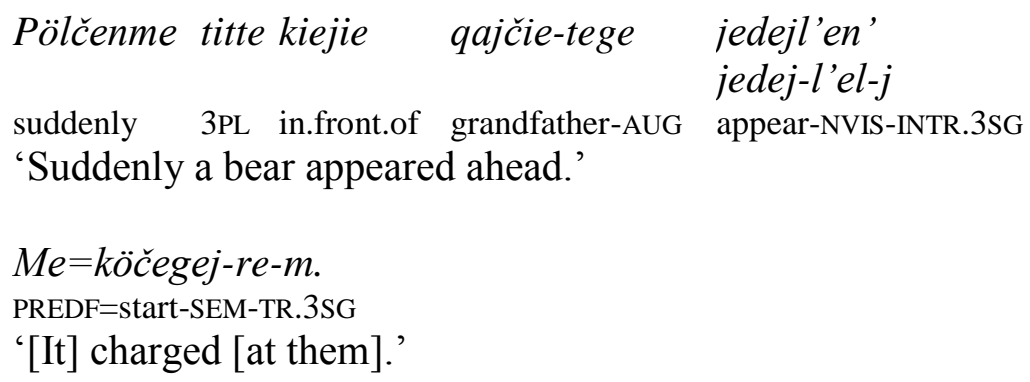

(Kurilov 1994:12)

There is no doubt that the sole purpose of the first two sentences is to introduce successively two new topics. In the third sentence they represent given information and are spoken about, which is signaled by their omission. The first two sentences are thus clearly presentative ones but the predicates in both of them are encoded as $\mathrm{BC}$ forms. What could be the reason for the use of the $\mathrm{BC}$ form of the verb in the RPS in this example? Given the status of this sentence as being presentative, i.e. one in which the functions of focus and topic are combined in one constituent, focalizing of the adverb "suddenly" appears impossible on pragmatic grounds, since manner adverbs are not established as topics in narrative texts. In other words, it would have to be the topic of this sentence that gets focalized. Besides, there are instances of very similar RPSs that contain SF verb forms, which shows that the choice of the BC verb form is not obligatory in presentative sentences containing a focal peripheral constituent:

$$
\begin{aligned}
& \text { Aarej purewre-t anme jaqte-ley möruu-l. } \\
& \text { stop above-ABL suddenly song-FOC be.heard-NMLZ.SF } \\
& \text { 'Then, suddenly, a song was heard / resounded from above.' }
\end{aligned}
$$

(Krejnovič 1982:189)

The situation in (13c) could be explained in the following way. The status of its second sentence as RPS is relative because there has hardly been anything in the text that has already been spoken about. The narration is so far practically free of the preexisting context. Therefore the second sentence could be considered a counterpiece of the first sentence necessary to set the scene. Such interpretation allows regarding the second sentence also as APS, whose predicates as will be seen further are far less rigidly encoded as SF forms. The sentence in (13d), on the other hand, appears in a text after a young man that had been established as the topic in the introductory sentence of that text had been spoken about for quite a while. Therefore there is a need to mark the transition to a next topic in a very clear manner, of which seemingly only sF forms are capable.

Another potential explanation for the focal pattern of the RPS in (13c) is connected with the fact that, as will be seen in section 6, emphasis is expressed in TY with the same grammatical means as focus. In this sense focus and emphasis can be equated in TY. Given the strong overall tendency for focal peripheral constituents to be focalized and since focalization and emphasis can be equated with respect to the formal means of their expression in TY, one can assume that there is a competition between the focal topic of this sentence and the peripheral constituent for the formal assignment of the function of focus and emphasis respectively. Since intra-clausal focal patterns of TY are complementary, the speakers have to opt for one of these, either focalizing the new topic or emphasizing the peripheral constituent. With this interpretation, one would have to conclude that in this particular instance the narrator decided to give preference to 
the emphasis over the focus. The same reasoning could be applied to account for the corresponding focus pattern in (13b), which, unlike the RPS in (13c), by no means can be regarded as APS, which, as will be seen in the following, can in a number of instances display the BC pattern instead of the SF pattern.

Native speakers of TY (Kurilov, personal communication) confirm that for the sentence in (13b) to accentuate pragmatically the topic it would have to follow the SF pattern:

\section{(13e) Taynigine čii-n l'oura-l-ek l'e-l. then people-RLN play-NMLZ-FOC be-NMLZ.SF \\ 'In those times there used to be a festival.'}

Analysis of textual material reveals that there is more variation in encoding focal topics in APSs. Numerically SF prevails as with RPSs but BC does not produce an impression of an exceptional phenomenon at all. In fact, these two encoding patterns occur almost evenly. Out of 11 APSs found in Kurilov's book of children stories in 5 of them the predicate is encoded as BC form of the verb. Regularity can be observed there. The verb l'e- 'to be' always appears in its SF. Another existential verb, sayane- 'to live' occurs both in its SF and BC form. All other verbs introducing a new topic, those with the meaning of coming into appearance, are used only in their BC forms. A few examples illustrate that:

(14a) N'id'anmijil-pe-k l'e-yu-l, ...

brothers-PL-FOC be-PL-NMLZ.SF

'There were two brothers, ...'

(Kurilov 1991:30)

(14b) Sal'il tadaat qawd'idie Qaalid'e sayane-yi.

mouse and uncle Wolf sit-3PL.INTR

'There lived a mouse and the Uncle Wolf.'

(Kurilov 1994:8)

(14c) Sal'il tude nime tuduruu-t ölkie-j.

mouse 3.SG house inside-ABL run.INCH-INTR.3SG

'A mouse came out running from its hole.'

(Kurilov 1994:55)

With APSs even PREDF of the verb can be encountered ${ }^{27}$ :

(14d) Qajčietege n'awn'ikle-n'ey me=n'i-nuu-ni.

bear arctic.fox-COM PREDF=RECP-find-INTR.3PL

'A bear and a polar fox met.'

(Kurilov 2005 as cited in Matić and Nikolaeva 2008:4)

It could be argued that (14d) is not a genuine presentative sentence due to the lexeme choice for the predicate. But in my view the verb is semantically empty here. It is not essential whether the

\footnotetext{
${ }^{27}$ The reflex of the original lexical mening of the verb seems to play a role in the choice of the focus pattern of the predicate in presentative sentences. The more lexical content there is, the sooner the predicate is encoded as the BC or even PREDF verb form.
} 
protagonists met, dined together or fought. The verb solely describes the circumstances in which the participants became important for the narration. They are clearly accentuated, not the action. The lexical emptiness of the verbal predicate in (14d) becomes especially clear when it is confronted with (14e), the first sentence of a story too, where the predicate delivers along with the subject an essential piece of information. For this reason the sentence cannot be regarded as presentative but should be viewed as an 'all-new' sentence whose predicate is predictably encoded as PREDF form.

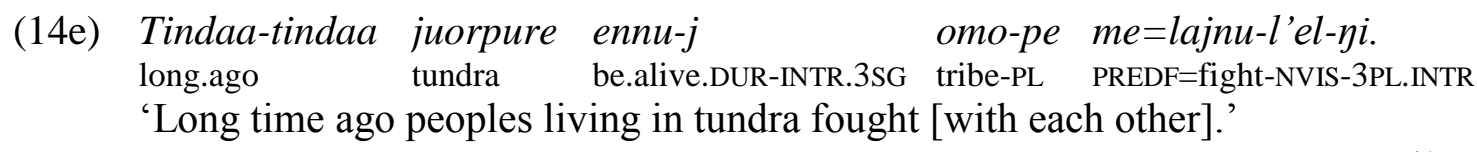

(Kurilov 1994:38)

The less consistent encoding of focal topics in APSs as SF may result from the fact that since they occur in the beginning of a text there is less pragmatic pressure to label them as such for the lack of competitive preexisting topics. They are so to speak the only available topics, which accounts for the choice of the default BC form of the verb and the basic form of the subject. The new topics within a narration cannot be recognized as readily as such by the listener unless the speaker uses a device, the SF marking, to signal that the subject spoken about has changed.

Considering a relatively widespread use of $\mathrm{BC}$ verb forms in APSs, it has to be postulated that this encoding pattern apart from focalizing a peripheral constituent has a default function and is chosen when no particular constituent of a clause needs to be emphasized (see also sections 4 and 6), which in view of the above-said probably is the case in APSs.

\subsection{Contrastive foci and contrastive topics}

These two categories are treated together because elicitations have shown that they are encoded mainly in the same way. The morphological devices employed are the same as those for marking focus. While their usage in contrastive foci can be conditioned by the necessity to mark focus, in contrastive topics they can only serve to mark contrast.

In terms of Dik (1997, 1:330-334) contrastive foci are represented by the focus types Replacing and Expanding while contrastive topics are exemplified by the types Rejecting, Restricting, Selecting. A sixth type, the so called Parallel (contrastive focus) is characterized by the simultaneous occurrence of two pairs of contrastive constituents in the same sentence. One of them is focal, the other one is normally topical. The fuller forms of Expanding and Restricting as well as the combination of Rejecting and Replacing necessarily involve more than one SA with multiple pragmatic functions.

The encoding of contrast is systematically illustrated with the example of contrastive predicates (expressed by intransitive verbs ${ }^{28}$ ) because in them contrast is expressed in a most consistent way throughout all six types of contrastive focus within Dik's (1997) classification. The encoding of contrast in intransitive verbs shows also the least degree of divergence from speaker to speaker.

\footnotetext{
${ }^{28}$ Contrastive predicates expressed by transitive verbs morphologically behave in the same way as those expressed by intransitive verbs. The only divergence is observed with Parallel (contrastive focus) where the first predicate is encoded as BC form of the verb. Since the corresponding sentence was elicited from one person only, it cannot be taken into this account as a fully reliable piece of information but has to be confirmed with other speakers first.
} 
The subscript capital letter ${ }_{C}$ stands in the following presentation for 'contrast'.

$\mathrm{SV}_{\mathbf{C}}$

Replacing:

(15a) Uo mer=ayal'waa-nu-j. - Elen', tudel mer=oorin'aa-nu-j.

child PREDF=laugh.INCH-DUR-INTR.3SG NEG 3SG PREDF=cry.INCH-DUR-INTR.3SG

'The child is laughing.' - 'No, it is crying.'

Expanding:

(15b) Uo mer=ayal'waa-nu-j.

child PREDF=laugh.INCH-DUR-INTR-3SG

Tudel wajide mer=iimid'ie-nu-j.

3SG still PREDF=dance.INCH-DUR-INTR.3SG

'The child is laughing.' - 'It is also crying.'

Rejecting:

(15c) Uo mer=aawaa-j. - Elen', tudel el aawaa- $\emptyset$.

child PREDF=sleep.INCH-INTR.3SG NEG 3SG NEG sleep.INCH-3SG

'The child fell asleep.' - 'No, it did not fall asleep.'

Restricting:

(15d) Uo ayal'waa-nu-rey mer=iimid'ie-nu-j. ${ }^{29}$

child PREDF=laugh.INCH-DUR-CVB PREDF=dance.INCH-DUR-INTR.3SG

Elen', tudel maarquon' mer=ayal'waa-nu-j.

NEG 3SG only PREDF=laugh.INCH-DUR-INTR.3SG

'The child is laughing and dancing.' - 'No, it is only laughing.'

Selecting:

(15e) Uo mer=ayal'waa-nu-j ejk mer=iimid'ie-nu-j?

child PREDF=laugh.INCH-DUR-INTR.3SG or PREDF=laugh.INCH-DUR-INTR.3SG

Tudel mer=ayal'waa-nu-j.

3SG PREDF=laugh.INCH-DUR-INTR.3SG

'Is the child laughing or dancing?' - 'It is laughing.'

Parallel:

(15f) Lasu taat Motuu n’i-könmii-pe-ley.

Lasu so Motuu RECP-stay.together-PL-COP

'Lasu and Motuu are husband and wife.'

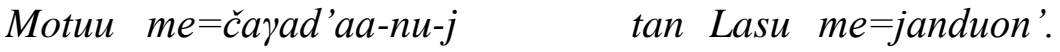

Motuu PREDF=work.INCH-DUR-INTR.3SG and Lasu PREDF=sleep.INTR.3SG

'Motuu is working and Lasu is sleeping.'

\footnotetext{
${ }^{29}$ Speakers' opinions vary on whether the focal clitic me may be used with the finite verb form if a converb occurs in the same sentence. It seems that the clitic must be absent if the converb carries focal information.
} 
From (15a-15f) it becomes clear that the function of the verbal clitic me is not confined to encoding focus but covers contrast too. With intransitive verbs, there is only one instance of a contrastive predicate expressed by the affirmative form of a verb that does not carry the focus/contrast marker. It is found in the fuller form of Expanding:

(15g) Uo mer=ayal'waa-nu-j.

child PREDF=laugh.INCH-DUR-INTR.3SG

\begin{tabular}{|c|c|c|c|}
\hline $\begin{array}{l}\text { Tudel } \\
3 \mathrm{SG}\end{array}$ & $\begin{array}{l}e l \\
\text { NEG }\end{array}$ & $\begin{array}{l}\text { maarquon' } \\
\text { only }\end{array}$ & $\begin{array}{l}\text { ayalawaa-nu-j } \\
\text { laugh.INCH-DUR-INTR.3SG }\end{array}$ \\
\hline & wajide & mer $=$ iimid & 'ie-nu-j. \\
\hline & & PREDF= laugh & 1.INCH-DUR-INTR.3SG \\
\hline
\end{tabular}

'The child is laughing.' - 'It is not only laughing but also dancing.'

A comparable sentence pair with transitive verbs repeats this pattern. It could be speculated, therefore, that in case more than one affirmative ascriptive SA with multiple pragmatic functions is present in a sentence, only that expressing focus gets the focus/contrast marker, which makes it reasonable to consider focus and contrast separate pragmatic functions despite the fact they are encoded in the same way in TY.

With contrastive arguments ( $\mathrm{S}$ and $\mathrm{O}$ ) the picture is not so uniform. Normally they carry the focus/contrast markers as in (16a) and (16b):

$\mathbf{S}_{\mathbf{C}} \mathrm{V}$

Replacing:

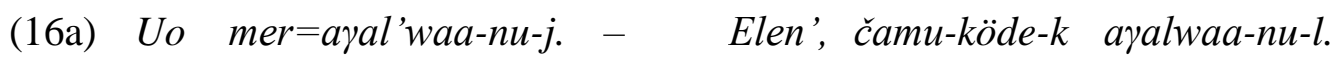

child PREDF=laugh.INCH-DUR-INTR.3SG NEG big-man-FOC laugh.INCH-DUR-NMLZ.SF

'A child is laughing.' - 'No, it is an adult [who] is laughing.'

$\mathrm{A} \mathbf{O}_{\mathrm{C}} \mathrm{V}$

Selecting:

(16b) Uoy purie-ley aptaa-nu-mle ejk samnaldayn'e-le?

child berry-FOC gather.INCH-DUR-TR.3SG.OF or mushroom-FOC

'Is the child picking berries or mushrooms?'

Uoy purie-ley aptaa-nu-mle.

Child berry-FOC gather.INCH-DUR-TR.3SG.OF

'The child is picking berries.'

While focus/contrast markers are consistently attached to contrastive topics (16b) and to contrastive focal S (16a), this does not happen with contrastive focal $\mathrm{O}$. It is unclear yet whether it is a systematic phenomenon.

The extreme is represented by speakers in whose speech all contrastive arguments systematically lack the nominal focus markers. Their predicate is then used in its BC form: 
$\mathbf{S}_{\mathbf{C}} \mathrm{V}$

Replacing:

(17a) Uo mer=ayal'waa-nu-j.

child PREDF=laugh.INCH-DUR-INTR.3SG

Elen', čama köde aral'waa-nu-j.

NEG big man laugh.INCH-DUR-INTR.3SG

'A child is laughing.' - 'No, an adult is laughing.'

$\mathrm{A} \mathbf{O}_{\mathrm{C}} \mathrm{V}$

Selecting:

(17b) Uo purie-le ejk samnaldayn'e-le aptaa-nu-m?

child berry-ACC or mushroom-ACC gather.INCH-DUR-TR.3SG

'Is the child picking berries or mushrooms?'

Uo purie-le aptaa-nu-m.

child berry-ACC gather.INCH-DUR-TR.3SG

'The child is picking berries.'

Given the existence of a specific way of encoding OF (some speakers consistently use the basic conjugation forms to encode $\mathrm{OF}$ as long as the subject is $3^{\text {rd }}$ person, see section 9.2 on paradigmatic deviations) and considering the observation that focus and contrast are encoded in the same way, the encoding of contrastive objects as in (17b) is not surprising. Unlike that, the failure to use nominal focus/contrast markers with contrastive $\mathrm{S}$ cannot be accounted for by assuming a subsystem because their omission is not systematic from speaker to speaker and even with the same speaker. Remnants of the expected patterns can be found in speakers, who otherwise use basic forms in sentences with contrastive $\mathrm{S}$, in the combination Rejecting + Replacing and in the fuller form of Restricting of which the latter is illustrated in $(17 \mathrm{c})$ :

$\mathbf{S}_{\mathbf{C}} \mathrm{V}$

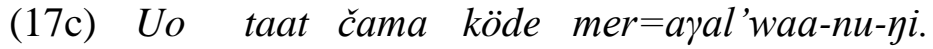

child so big man PREDF=laugh.INCH-DUR-3PL.INTR

'A child and an adult are laughing.'

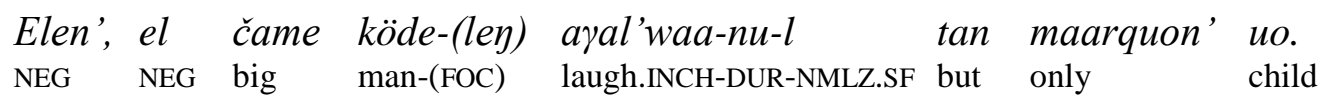

'No, it is not an adult [who] is laughing but (only) a child.'

The fact that some speakers allow both SF and basic forms for the combination Rejecting + Replacing means that the shift from the focal/contrastive forms to the basic forms is ongoing. This shift can be viewed as a sign of the overall tendency toward simplification by generalization in younger speakers of TY.

An interesting pattern was observed in Parallel contrast of S: 

Me $=$ kinek
aral'we-juol-gi ${ }^{30}$
тӧrии-l
$\mathrm{IDF}=$ who
laugh-RES-POSS
be.heard-NMLZ.SF
$m e=k i n e k \quad m e=j a q t e-j$.
IDF=who PREDF=sing-INTR.3SG

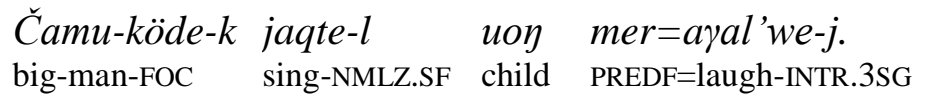
'It could be heard that someone laughed and someone sang. It was an adult [who] sang, a child laughed.'

In the second sentence in (18) only one of the two contrastive arguments carries the nominal focus/contrast marker and has the predicate in the SF form. The other appears in its basic form accompanied by the predicate in the PREDF form. It has yet to be confirmed, whether this is a systematic restriction.

As far as the encoding of contrastive A is concerned, there are two different strategies. It can be done by purely syntactic means switching from the unmarked AOV word order of TY to AVO. Speakers applying this strategy do it quite consistently. The only exception is the Restricting type of contrast where the usual AOV word order is observed. This may be conditioned by the fact that restrictive sentences are normally formed with the help of the words like 'only'. Possibly this lexical device is considered sufficient for expressing contrastive meaning. Morphologically both the contrastive argument and its predicate are basic forms. Interestingly, speakers resorting to syntactic means to present A contrastively assign the function of focus to it in the same way, which is another indication that these pragmatic functions merge in the cognitive apparatus of TY speakers. Consider the following examples:

$\mathbf{A}_{\mathbf{C}} \mathrm{OV}$

Selecting:

(19a) Purie-le aptaa-nu-m uo ejk čama köde?

berry-ACC gather.INCH-DUR-TR.3SG child or big man

'[Is it] a child [who] is picking berries or an adult?'

Uo aptaa-nu-m purie-le.

child gather.INCH-DUR-TR.3SG berry-ACC

'[It is] a child [who] is picking berries.'

$\mathrm{A}_{\mathrm{F}} \mathrm{OV}$

(19b) Kin-ek lalime-le sal'yarej-m? - Ieruu-če sal'yarej-m lalime-le. who-FOC sledge-ACC break-TR.3SG hunt-NMLZ break-TR.3SG sledge-ACC

'Who broke the sledge?' - 'A/the hunter broke the sledge.'

\footnotetext{
${ }^{30}$ The nominal focus/contrast marker is not attached to the possessive marker in TY.
} 
The other strategy combines syntactic and morphological means. The encoding pattern corresponds to the one expected for encoding focal A: zero-ending forms of the contrastive argument and the predicate. A occupies the preverbal position ${ }^{31}$ :

$\mathbf{A}_{\mathbf{C}} \mathrm{OV}$

Selecting:

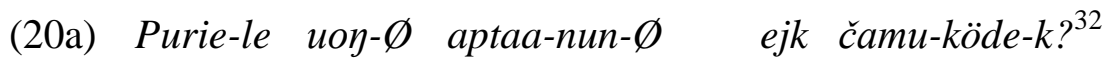

berry-ACC child-AF gather.INCH-HAB-AF or big-man-COP

[Is it] a child [who] picks berries or an adult?

Purie-le uoy- $\varnothing$ aptaa-nun- $\varnothing$.

berry-ACC child-AF gather-HAB-AF

[It is] a child [who] picks berries.

Putting A in the immediate preverbal slot can by itself testify of the contrastive usage of A as in the second sentence in $(20 \mathrm{~b})$.

Parallel:

(20b) Uorpey purie-le tadaat samnaldayn'e-le aptaa-nun-ya.

child.PL berry-ACC and mushrooms-ACC gather.INCH-HAB-3PL.TR

'Children pick berries and mushrooms.'

Purie-le paad'eduorpe aptaa-nun-ya

berry-ACC girl.PL gather.INCH-HAB-3PL.TR

tan quod'eduorpe samnaldayn'e-le.

and boy.PL mushrooms-ACC

'Girls [are those who] pick berries and boys [are those who] pick mushrooms.'

(19a) and (20b), with the generalized word order (O)AV(O), in which syntax is the only means to assign the pragmatic function of focus/contrast, might be indicative of the role syntax is acquiring in encoding information structure in modern TY. It appears that to enable syntax to determine the focal/contrastive status of the main constituents, is another function of the $\mathrm{BC}$ form of the verb.

Summarizing, it can be said that the pragmatic function of contrast is encoded with the same morphological means that are used do denote focus on the respective constituent. Deviations from this can be attributed to either language change or the decreasing linguistic competence of some speakers and are, apparently, additionally conditioned by the preference of syntactic means for encoding contrast over the morphological ones.

\footnotetext{
${ }^{31}$ According to Kurilov (personal communication), the constituent immediately preceding the predicate is emphasized. Note that the verb retains its clause-final position, which is more natural for TY than the word order AVO occurring in (19a).

${ }^{32}$ The ending $-k$ here probably is not the focus/contrast marker but the device it developed from:the copula. The corresponding portion of the sentence would have to be understood then as a copular sentence: '... or is it an adult?'
} 


\section{The Verbal Clitic me}

Whereas the function of the nominal focus markers $-l e(\eta)$ and $-(e) k$ is quite obvious, the function of the verbal clitic me is not so transparent. In his early work Krejnovič (1958:39) called the verb forms with this clitic "affirmative/assertive-predicative conjugation" 33 as opposed to the verb forms serving to emphasize the core arguments. In his account Krejnovič (1958:150-151) enlists a number of conditions in which the clitic me can be dropped. For the discussion of the focus system only two of them are important because they concern verbal forms participating in the morphological marking of the function of focus, namely finite verbs in affirmative ${ }^{34}$ indicative sentences. Only one of the two conditions is formal: the presence of a qualitative adverb. The other condition is the lack of the necessity to emphasize the verb. This condition is formulated and illustrated somewhat vaguely. In his later work Krejnovič (1982:187ff) does not take into account the omission of the clitic me any longer, grouping the verb forms with and without it in the same category labeled as 'rank I predicates' as long as they display the same person/number endings. The predicates from this category carry new information and characterize a known subject, while the rank II and III predicates (in this work they correspond to SF/AF and OF respectively) do not carry new information.

A decade later scholars showed renewed interest in this issue. One of the main points in Comrie's (1992) article is that the omission of me takes place when a peripheral constituent is in focus. Fortescue's (1996:22) analysis led him to say that the functions of the clitic me were the narrow focus on the predicate itself and the wider focus foregrounding the whole predication. The verb forms belonging to the rank I predicates in Krejnovič's (1982) terminology and not accompanied by the clitic me, Fortescue (1996:20) regards as default indicative forms in most cases unmarked for their focal status.

The latest academical contribution dealing with the clitic me, an unpublished article by Matic and Nikolaeva (2008), is concerned with the cliticized verbs only. The authors come to a similar preliminary conclusion Fortescue (1996) made, namely that the clitic me ,signals that the main verb is focused, without further specification of the focus scope" (Matic and Nikolaeva 2008:5). With the help of numerous examples they convincingly demonstrate that me can express broad focus that includes constituents other that the predicate itself and the narrow focus on the predicate alone. For determining the type of narrow focus they provide the following interpretational hierarchy: focus on the lexical content of the verb

focus on the polarity

focus on TAM

pragmatic enrichment of the content of the verb

\footnotetext{
${ }^{33}$ The original Russian label is utverditel'no-predikativnaja forma sprjaženija (Krejnovič 1958:39). The alternative translations thereof into English derive from the alternative possibilities of interpreting it. As it appears from the description - Krejnovič (1958) points out the complementary usage of the clitic $m e$ and the negation clitic $e l$ - the term is employed with the meaning 'affirmative'. However, the following presentation of the focus system of TY in which the clitic me is involved, accompanied by the invocation of the notion mentioned in footnote 3 , hints at the opposition 'presupposed/asserted information'.

${ }^{34}$ In the section dedicated to the expression of the focus in negative sentences it will be demonstrated that the focal patterns known from the affirmative paradigms are found in negative sentences as well, except that PREDF and focus on a peripheral constituent cannot be discerned morphologically.
} 
My own observations confirm the conclusions made by Matić and Nikolaeva (2008) ${ }^{35}$ and enrich them with a few new facts. My data (see section 2.3) also support Comrie's (1992) proposal of an additional focus type for TY, manifest when the focal constituent is not one of the main constituents of the sentence.

I would like to begin the discussion with two phenomena I was able to detect in TY that up to now were considered ungrammatical in the literature. They concern the allegedly obligatory usage of the clitic me in verb-only clauses and the obligatory omission thereof in sentences with qualitative adverbs ${ }^{36}$.

It is true that all speakers normally use $m e$ in verb-only clauses and some of them reject verbonly sentences without it as incorrect. However, a considerable number of them, including elderly people ${ }^{37}$, accept verb-only clauses without me as in (21a) and (21b) or at least do not consider them as entirely incorrect.

Uo $\quad$ mer $=$ oorin'aa- $n u-j$ ?

child PREDF=cry.INCH-DUR-INTR.3SG

'Is the child crying?'

Elen' el oorin'aа-nu-Ø, aүal'waa-nu-j.

NEG NEG cry.INCH-DUR-3SG, laugh.INCH-DUR-INTR.3SG

'No [it] is not crying, [it] is laughing.'

\section{(21b) Tudel me=kelu-j? - Kelu-j.}

3SG PREDF=come-INTR.3SG come-INTR.3SG

'Did he come?' - '[He] came.'

This usage is definitely substandard, but the degree of its incorrectness does not even approach that of what would be considered by all native speakers a grave error, such as wrong agreement ending. One elderly speaker claimed that the cliticized forms and those without me could be used interchangeably since there was absolutely no change in the meaning:

\section{Uo leme-ley wie-nu-mle? - (Mer)=ayal'waa-nu-j. child what-FOC do-DUR-TR.3SF.OF (PREDF)=laugh.INCH-DUR-INTR.3SG} What is the child doing? - [It] is laughing.

There is even more tolerance toward the uncliticized form when the predicate is represented by a so called qualitative verb:

(23a) Tet nime me=wejluon'? - Wejluon'.

2SG house PREDF=be.wide.INTR.3SG be.wide.INTR.3SG

'Is your house spacious?' - '[It is] spacious.'

\footnotetext{
${ }^{35}$ Except the categorical claim that $m e$ must be used in case of the narrow predicate focus. See section 5 in this regard.

${ }^{36}$ Comrie (1992:62) was possibly the only one who noticed that the latter was not true, bringing a counter example from Kreinovič (1958).

${ }^{37}$ Even the late mother of some of the elderly informants used to form verb-only sentences without $m e$. So, this phenomenon cannot be attributed to the loss of linguistic competence of the speakers.
} 

Tet ile
$m e=\check{c} a a l$ 'uon'
uuri me=n'aawe-j.
$2 \mathrm{SG}$ reindeer
PREDF=be.bay.INTR.3SG
or
PREDF=be.white-INTR.3SG

N'aawe-j.

be.white-INTR.3SG

'Is your reindeer bay or white?' - [It is] white.

With verbs derived from nouns the clitic me is used in polarity questions to ask for a mere confirmation of already known information (24a). When the inquiring person does not anticipate the answer, the clitic is omitted (24b). The answer invariantly repeats the focal pattern of the question.

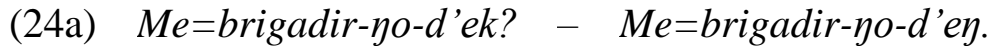

PREDF=team.leader-be-INTR.2SG PREDF=team.leader-be-INTR.1SG

'[You $]$ are a/the team-leader, [aren't you]?' - '[I] am a/the team leader.'

(24b) Brigadir-yo-d'ek? - Brigadir-yo-d'ey.

team.leader-be-INTR.2SG team.leader-be-INTR.1SG

'Are [you $]$ a/the team-leader?' - '[I] am a/the team-leader.'

(24a) provides the first evidence that the clitic me can be detached from the function of focus and express emphasis alone (see also (26a) and (26b)).

Verbal forms expressing possession can also occur without me if it is not present in the question:

Ile-n'e-jek? - Ile-n'e-jey.

reindeer-COM-INTR.2SG reindeer-COM-INTR.1SG

'Do [you] have reindeer?' - '[I] have reindeer.'

With the quantitative verbs, the clitic $m e$ is preferably dropped in verb-only clauses because otherwise the idea of limitation is stressed too much:

(26a) Maarqad-aduo-n'e-j.

one-son-COM-INTR.3SG

'[He] has one son.'

(Krejnovič 1982:185)

(26b) Me=maarqad-aduo-n'e-j.

PREDF=one-son-COM-INTR.3SG

'[He] has only one son.'

As one can see in (26a), verb-only clauses without the clitic me are not a new discovery. In fact, corresponding examples could be found already in Kreinovič's (1958) earlier work: 
L'iteguod'en.

be.beaten.INTR.1SG

'[I] was beaten.'

(Krejnovič 1958:259)

There are three instances of verb-only sentences describing seasonal changes in the text that contains (27). All of them lack the clitic me. One of them is quoted in (28).

(28) Lewejl-yol-a-j.

summer-be-INCH-INTR.3SG

'Summer arrived.'

(Krejnovič 1958:256)

The above quoted examples prove that there is a wide array of verb-only sentence types in which the clitic me does not occur with various degree of obligation. Lest a wrong impression arise, be it repeated that with verbs that are sometimes designated as 'dynamic' me does normally occur, but there is no absolute prohibition of its omission.

As for the obligatory omission of me in sentences with qualitative adverbs, the following sentences relativize it. They are taken from a short children story in which a girl named L'al'uu finds a snow crane with an injured wing and intends to treat it:

(29a) L'al'uu marl'e-ley men'-mele. Amutney mer=iire-m.

L'al'uu gauze-FOC take-TR.3SG.OF be.good.ADV PREDF=bind-TR.3SG

'L'al'uu took gauze. [She] bandaged [the wing] well.'

The search for similar examples in the earlier primary sources brought to light three comparable sentences two of which are quoted in (29b) and (29c).

(29b) Anil'-da-yane waariney mer=iire-m.

opening-POSS-ACC be.firm.ADV PREDF=bind-TR.3SG

' $[\mathrm{He}]$ bound tightly its opening'

(Kreinovič 1982:273)

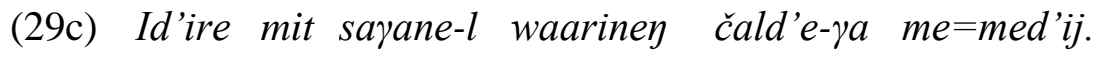

now 1PL sit-NMLZ be.firm.ADV hand-LOC PREDF=take.TR.1PL

'Now [we] have firmly taken our life in [our] hands.'

(Kreinovič 1958:202)

Again, there is undoubtedly a strong tendency for the omission of me in sentences with qualitative adverbs because in most cases the narrow focus on the adverb is intended, but it has to be recognized that it is only a tendency, not an absolute rule.

It has been established in section 2.3 that the clitic me is dropped in sentences whose sole focal constituents are peripheral. There are, however, instances in which a focal peripheral constituent co-occurs with a focal cliticized verb. The following example illustrating that is the opening sentence of a children story. 
Qomdeme juorpure lewejl'e juorpure-yat me=wiedeban-i.

autumn tundra summer.ATTR tundra-ABL PREDF=be.different-INTR.3SG

'The autumnal tundra differs from the summer tundra.'

(Kurilov 1994:14)

Since it can be counted as proven that the presence of me normally indicates predicate focus and the emphatic function does not irresistibly suggest itself in the case of (30), the notion of broad focus postulated for TY by Matić and Nikolaeva (2008) is a very plausible solution. Broad focus that includes the verb explains probably, at least partly, also the presence of the clitic me in sentences like the ones in (29a), (29b) and (29c). The idea of the specific focus domain 'predicate + peripheral constituent' is particularly lucky because it reconciles the fact, that patterns in (29a), (29b), (29c), (30) and in many other instances are attested in TY, with the first hierarchy established for the choice preference when encoding focus in sentences with multiple focal constituents: $\mathrm{X}_{\mathrm{F}}>\mathrm{V}_{\mathrm{F}}$. The use of the clitic me in sentences containing focal predicate and focal $\mathrm{X}$ might be simply the way of neutralizing the otherwise obligatory narrow $\mathrm{X}$ focus reading, letting the focal interpretation of an utterance spread over the whole predication.

Another interesting issue is the usage of $m e$ in sentences that do not carry peripheral constituents. Here the particle $m e$ is normally present as long as the predicate is focal:

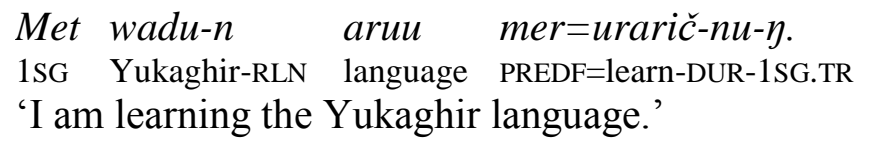

It is not ungrammatical though to omit it. Since there is no peripheral constituent to produce the corresponding narrow focus by such an omission, there has to be another effect. Informants claim that the omission of me in (31) and similar simple sentences, also with intransitive verbs, would produce an utterance made in a 'matter of fact' way, or in passing, or as if in hurry, often conditioned by the mood of the speaker. This lack of expressivity can be taken as another indication that me has some emphatic function.

Summarizing the above it can be stated that:

- $\quad m e$ focalizes the predicate (but see section 5)

- $m e$ is omitted in clauses with the narrow $\mathrm{X}$ focus

- $m e$ is retained in clauses with focal $\mathrm{X}(\mathrm{s})$ if the predicate belongs to the focus domain; the presence of $m e$ indicates then that there is no narrow $\mathrm{X}$ focus in the clause

- $\quad m e$ can be omitted in sentences without $\mathrm{X}$, indicating a decrease of expressivity

The emphatic use of me will be an object of closer examination in section 6 .

\section{Narrow Focus on the Predicate Accompanied by a Qualitative Adverb.}

Adverbs are verbal modifiers. In section 2.3 the narrow focus on them is described. The cliticized form of the verb has been recognized as testifying of the presence of the broad focus in the presence of a peripheral constituent, such as an adverb. The logical question to be posed is how the narrow focus on the modified member in this relation, the verb, is encoded. It is especially interesting to find this out for instances in which a manner adverb serves as the 
modifier, since manner adverbs show the least tolerance toward the presence of the clitic me, that is the device for marking predicate focus. Elicitations have shown that it is achieved through the nominalization of the verb which becomes the subject of the sentence while the adverbial peripheral constituent is verbalized and promoted to the position of the predicate:

$$
\begin{aligned}
& \text { Tiey köde neme-le wie-l-gi amuč? } \\
& \text { DEM man what-FOC do-NMLZ-POSS be.good.INTR.3SG }
\end{aligned}
$$

Tudel iimid'ie-l-gi amuč.

3SG dance.INCH.-NMLZ-POSS be.good.INTR.3SG

'What does that man do well?' - 'He dances well.'

Instead of the nominalized form of the verb, its converb form can be used. This means, in effect, that the predicate and the peripheral constituent (a manner adverb) of the underlying sentence exchange their functions in the surface structure. In other words, peripheral constituents rank so high in the focus assignment hierarchy that the predicate accompanied by a peripheral constituent, in order to be assigned the function of narrow focus has to be converted into a peripheral constituent, pushing the peripheral constituent of the underlying sentence out of this privileged syntactic slot and making it fill the less privileged predicate slot:

(32b) Lasu neme-le wie-r amdu-nun-Ø?

Lasu what-FOC do-CVB haste-HAB-3SG.ITRG

Lasu miraa-r amdu-nun-i.

Lasu walk.INCH-CVB haste-HAB-3SG.INTR

'What does Lasu do quickly?' - 'Lasu walks quickly.'

The following examples demonstrate the narrow contrast on the predicate.

Restricting:

$\begin{array}{llll}\text { (33a) Lasu quodey } & \text { lewde-l-gi } & \text { amuč } \\ \text { Lasu how } & \text { eat-NMLZ-POSS } & \text { be.good.INTR.3SG }\end{array}$

taat čayad'e-l-gi amuč.

so work-NMLZ-POSS be.good.INTR.3SG

Elen', maarquon' lewde-l-gi amuč.

NEG only eat-NMLZ-POSS be.good.INTR.3SG

'Lasu eats and works well. - No, [he] only eats well.'

Selecting:

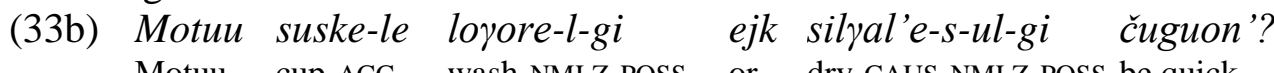

Motuu cup-ACC wash-NMLZ-POSS or dry-CAUS-NMLZ-POSS be.quick

'Did Motuu wash or dry the dishes quickly?' 
Motuu suske-le loyore-l-gi čuguon'.
Motuu cup-ACC wash-NMLZ-POss be.quick
'Motuu washed the dishes quickly.'

Parallel:

(33c) Lasu taat Motuu n’i-könmii-pe-ley.

Lasu so Motuu RECP-stay.together-PL-COP

Motuu čarad'e-l-gi n'aarčič

Motuu work-NMLZ-POSS be.good.INTR.3SG

tan Lasu janduo-l-gi n'aarčič.

and Lasu sleep-NMLZ-POSs be.good.INTR.3sG

'Lasu and Motuu are husband and wife. Motuu works bad and Lasu sleeps bad.'

It follows from the examples presented in this section that peripheral constituents in TY are such strong focus and contrast attractors that a special construction has to be applied in order to focalize or contrast exclusively the predicate in a sentence containing a peripheral constituent.

\section{Functional Scope of the Focus Markers in TY}

It has been shown in section 3.2 that the focus markers can fulfill the function of contrast markers as well. In section 4 the possibility of use of the verbal clitic me as an emphasis marker has been pointed out. The following examples, in my view, further strengthen, if not decisively prove, that assumption.
A: Tet me=möri-mek?
2SG PREDF=hear-TR.2SG
Motuи lajbuo-gi Lasu mer=antej-l'en'.
Motuu youngest.child-POSS Lasu PREDF=begin.to.speak-NVIS.INTR.3SG
B: Lasu antej-l'el-ul? El kin sukun mol'yal-čuol'uon'.
Lasu begin.to.speak-NVIS.-NMLZ.SF NEG two year joint-be.old.INTR-3SG
A: Tan l'ie mer=antejl'en'. and EMPH PREDF=begin.to.speak-NVIS.INTR.3SG
A: 'Have you heard? Motuu's youngest child Lasu has begun to speak.'
B: 'Lasu has begun to speak?! But he isn't even two years old yet.'
A: 'And yet, he has begun to speak.'

The SF focus marker in the second speaker's astonished question as well as the PREDF marker in the confirmation provided in the last sentence of this short dialogue cannot express focus in terms of the commonly accepted definitions of focus. The notion of focus is often connected with the idea of newness. However, the information conveyed by the constituents these focus markers 
are attached to, is not new. Maslova (1997) already established with all clarity for KY that the choice of a focus construction cannot be always explained in terms of the opposition 'given/new information'. I am making a similar observation for TY now with an essential addition. Focus is not just about the identity of a referent but also, and maybe even more importantly, about the relation it goes into. In the two last sentences of 34 the constituents carrying the focus markers contain information that is not new either in the sense of referent or relation. According to a modern definition of focus given by Smit (as cited in Hengeveld and Mackenzie (2008:89)), it is an "update instruction to the Addressee". The constituents in question could hardly be seen as carrying such an instruction. Neither do the focus markers here denote the "semantic component of a pragmatically structured proposition whereby the assertion differs from the presupposition", which is the definition of focus given by Lambrecht (1994:222). The sole purpose of the focus markers under scrutiny is apparently to put emphasis on the focalized constituents. Such instances are treated by Dik (1997, I:326-327) as focus, but this is a very broad definition of focus.

Resuming the above-said, all contrastive and emphatic uses of the focus markers in TY would have to be either lumped together as instances of focus after an appropriate modification of the definition of the focus concept or it would have to be recognized that those markers have a functional spectrum encompassing focus, contrast and emphasis. Within the theoretical framework chosen to present the data in this article, the latter solution is certainly preferable, not to speak of the former one's being unwarrantedly unorthodox.

\section{Focus in Negative Sentences}

Comrie (1992:64) claims, with a reference to Krejnovič (1958), that the focus opposition is lost in negative clauses in TY, stating, however, just a few sentences later that "the negative prefix is the focus, thus usurping the position of the predicate focus marker $m e(r)$ - and also preventing focus from being marked on any other constituent of the clause". The view that an argument cannot be focalized in negative sentences has persisted among scholars (see also Matić and Nikolaeva 2008:2). Krejnovič (1958) himself did not specifically express himself with respect to this question, merely giving the negative conjugational paradigm. It is the same for transitive and intransitive verbs and differs from the $\mathrm{BC}$ form of intransitive verbs only in $3^{\text {rd }}$ person as is clearly seen in the following overview from Krejnovič (1958:138, cf. the paradigmatic tables in 1.2).

$\begin{aligned} \text { SG1 } & \text { met el'ai-jey } \\ 2 & \text { tet el'ai-jek } \\ 3 & \text { tudel el'ai }\end{aligned}$

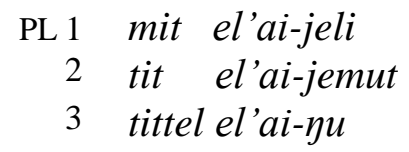

Since no other negative paradigms were established by Krejnovič, negative sentences of TY were considered focus neutral. The focus opposition indeed seems to be lost between predicate focus and focus on a peripheral constituent for formal reasons. In affirmative sentences this opposition is effected by the presence or absence of the focal clitic me (see section 2.3). But in negative sentences the predicate focus marker me is replaced by the negation particle $e l$, which, naturally, cannot be omitted, which, in turn, does not allow this opposition to come about. 
Contrary to the generally accepted view it is, however, quite possible to focalize arguments. Krejnovič (1958:140) already pointed at such a possibility. But his account suggests that only a modified focal object can carry a focus marker: ${ }^{38}$

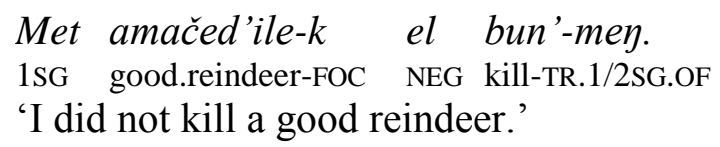

Other scholars for lack of primary data had to take this for granted. The phenomenon was regarded as a specific case and there were attempts to explain it as such. Krejnovič (1958) reasoned that with modified objects the negation was only partial. A completion of a transitive action in such sentences is negated only with respect to a certain representative of a class of referents, thus singling this representative out, presenting him contrastively and making it a constituent "deserving" the focal status. By the sentence I did not kill a good reindeer one can imply that one may have killed a bad reindeer. In such a context the direct object needs to be and is focalized in TY.

My data show that the focalization of arguments in negative sentences in TY is of a general nature. It can take place irrespective of the syntactic function of the arguments and does not depend on the presence of modifiers. The following examples illustrate that.

(36a) Kin-ek el kelu-l?

who-FOC NEG come-NMLZ.SF

'Who did not come?'

Uraričiiče-ley / n'id'erpe-j uraričiiče-k/Met-ek el kelu-l.
teacher-FOC / new-PTCP teacher-FOC / 1sg-FOC NEG come-NMLZ.SF
'The teacher / The new teacher / I did not come.'

(36b) Kin-ek el oorin'aa-nunu-l?

who-FOC NEG cry.INCH-HAB-NMLZ.SF

'Who does not cry?'

$\begin{array}{lllll}\text { Werwe-j } & \begin{array}{l}\text { čuyden'd'e } \\ \text { čuyden'-je }\end{array} & \text { čii-k } & \text { el } & \text { oorin'aa-nun- } n u-l . \\ \text { be.strong-PTCP } & \text { have.thought-PTCP } & \text { people-FOC } & \text { NEG } & \text { cry.INCH-HAB-PL-NMLZ.SF }\end{array}$

'Real men do not cry.'

(37a) Tudel neme-ley lew-nun-mele?

$3 \mathrm{SG}$ what-FOC eat-HAB-TR.3SG.OF

'What does he not eat?'

Tudel čuuley el lew-nun-mele.
čuul-ley
3SG meat-FOC NEG eat-HAB-TR.3sG.OF
'He does not eat meat.'

\footnotetext{
${ }^{38}$ It has to be admitted that Krejnovič (1958:140) quotes an example from Jochelson that involves a focalized pronoun in the negative context but he does not elaborate on it.
} 
(37b) Tudel kin-ek el kuril'ii-mele?

3SG who-FOC NEG know-TR.3SG.OF

'Whom does he not know?'

Tudel tet-ek el kuril'ii-mele.

3SG 2SG-FOC NEG know-TR.3SG.OF

'He does not know you.'

The assignment of the function of focus is not as consistent in negative sentences as it surely is in affirmative ones. Thus answers in (36a), (36b) and (37b) have in my material alternative patterns lacking the (pro)nominal focus markers and containing predicates that stand in what can be called the negative $\mathrm{BC}$ form. The speakers admit, however, that it is rather the action that is emphasized then. This is exemplified in (37c), an alternative answer to the question in (37b).

\section{(37c) Tudel tet-qane el kuril'ii- $\varnothing$. \\ 3SG 2SG-ACC NEG know-3SG \\ 'He does not know you.'}

It is indeed impossible to focalize an argument in yes-no negative interrogative sentences as it can be learnt from the existing accounts (Matić and Nikolaeva 2008:2).

In all the above sentences it was the predicate that was negated. In sentences containing a contrastive negation of an argument the corresponding focal pattern also occurs readily. The focus markers obviously fulfill the function of contrast in them. Compare the focal patterns of the sentences with an intransitive (38a) and (38b) and a transitive (39a), (39b) and (39c) verb. The negation particle is moved from the preverbal position to a position in front of the negated constituent.

(38a) Met el ayal'we-jey.

1SG NEG laugh-INTR.1SG

'I did not laugh.'

(38b) El met-ek ayal'we-l.

NEG 1SG-FOC laugh-NMLZ.SF

'[It is] not me [who] laughed.'

(39a) Met čuul el lewnund'è.

lew-nun-jey

1SG meat NEG eat-HAB-INTR.1SG

'I do not eat meat.'

(39b) Čuul el met- $\varnothing$ lew- $\varnothing$.

meat NEG 1SG-AF eat-AF

'[It is] not me [who] ate [the] meat.'

(39c) El čuuley lew-mey.

NEG meat.FOC eat-TR.1/2SG.OF

'[It is] not meat [that I] ate.' 
Just as in the case of affirmative sentences, the OF pattern obtains not only when the question triggers the narrow object focus but also when along with the object the predicate is focal $\left(\mathrm{A} \mathbf{O}_{\mathbf{F}} \mathbf{V}_{\mathbf{F}}\right.$ focus articulation):

(40a) Lasu neme-ley el wie-mele?

Lasu what-FOC NEG do-TR.3SG.OF

'What did Lasu not do?'

Tudel nimele-le(y) el počesej-l'el-mele.

$3 \mathrm{SG}$ letter-FOC NEG send-NVIS-TR.3SG.OF

'He did not send the letter.'

However, when the answer does not contain an object, the predicate expressed by a transitive verb loses both its transitivity marker and the OF marker appearing in its negative BC form:

(40b) Tudel el aji-l'el-Ø.

3SG NEG shoot-NVIS-3SG

'He did not shoot.'

The identical encoding of the focus articulations $A \mathbf{O}_{\mathbf{F}} \mathrm{V}$ and $\mathrm{A} \mathbf{O}_{\mathbf{F}} \mathbf{V}_{\mathbf{F}}$ both in affirmative and negative sentences along with the fact that the lack of an overt direct object results in preventing the encoding of the OF pattern even though the question (like in 40a) demands the of pattern, can be taken as an indication that there is a verb phrase in TY.

So far no example with focal A was presented in which the negation would scope over the whole predication (in (39b) it scopes only over A itself). As is the case with focalizing A in affirmative sentences, there is a degree of variation in encoding a focal or contrastive A. This is illustrated by the two following examples kindly elicited for me by Cecilia Odé.

A-Focus:

(41) Uorpe-die, kin-ek wajidek el juo-l n'awn'iklie-le? children-DIM who-FOC still NEG see-NMLZ.SF polar.fox-ACC

'Children, who has not yet seen a polar fox?'

Met-ek el juo-l n'awn'ikliey.

1SG-FOC NEG see-NMLZ.SF polar.fox

'I have not seen a polar fox.'

A-Contrast:

(42) Tet aq qan'iney n'awn'ikliey el juo-jek.

2SG EMPH ever polar.fox NEG see-INTR.2SG

'You have not ever seen even a polar fox.' 
$\begin{array}{llll}\text { Tet-ek } & n^{\prime} a w n ' i k l i e y & \text { el } & \text { juo- } \emptyset \text {. } \\ \text { 2PL-FOC } & \text { polar.fox } & \text { NEG } & \text { see-AF }\end{array}$

'It's you who has not seen a polar fox.'

Although these focus patterns deviate from the prototypical pattern of encoding AF which is characterized by the use of bare stems of the focalized A-argument and its predicate, their existence is undeniable and, with it, the claim is now fully substantiated that the morphological expression of focus in negative sentences is just as real and systematic a phenomenon as it is in affirmative ones.

Resuming, it can be said that the focus system of TY employs the same morphological means for marking focus both in affirmative and negative sentences. The only difference between the two categories of sentences is that in negative sentences there is no morphological differentiation between PREDF and the focus on a peripheral constituent. It is therefore reasonable to unite these two under the designation 'non-argument focus'. The argument focus comprises, as in affirmative sentences, the types SF, AF and OF.

\section{Focus in the Passive}

The presentation of the passive voice in Krejnovič (1958:119) takes up slightly more than half of a page. In his later work Krejnovič (1982) does not treat this topic at all. This might have been caused by the fact that this voice is a relatively rare morpho-syntactic phenomenon in TY grammar. The functioning of the focus system in the passive voice has not been elucidated even roughly, which makes it an intriguing topic of research.

The elicitations show that the passive voice, however marginal it may be as such in the language, is fully incorporated into the focus system of TY. Passive verb forms behave essentially as any form of an intransitive verb in the active voice showing thus three focal patterns: that of the focal subject (SF), the focal predicate (PREDF) and the focal peripheral constituent. This is illustrated in the following examples.

$\mathbf{S V}_{\mathbf{F}}$

(43) Tet me lejtejuod'ek? - (Met) me lejtejuod'ey.

Tet me=leitej-uol-jey (Met) me=leitej-uol-jey

2SG PREDF=recognize-PASS-INTR.2SG (1SG) PREDF=recognize-PASS-INTR.1SG

'Were you recognized?' - 'I was recognized.'

$\mathbf{S}_{\mathbf{F}} \mathrm{V}$

(44a) Kin-ek uraričiiče-lek leitej-uol-el?

who-FOC teacher-INS recognize-PASS-NMLZ.SF

'Who was recognized by the teacher?'

Uraričiičelek met-ek/ieruuče-ley lejtej-uol-el.

teacher-INS 1SG / hunter-FOC recognize-PASS-NMLZ.SF

'I / The hunter was recognized by the teacher.' 
$\mathbf{S V}_{\mathbf{F}}$ (ed'uosuol 'to get frightened')

\begin{tabular}{|c|c|c|c|}
\hline SG1 & met mer $=e d$ 'uosuod'e ${ }^{39}$ & PL1 & mit mer $=e d$ 'uosuod'eli \\
\hline 2 & tet mer $=e d$ 'uosuod'ek & 2 & tit mer=ed'uosuod'emut \\
\hline 3 & tudel mer=ed'uosuon' & 3 & tittel mer=ed'uosuolyi \\
\hline
\end{tabular}

$\mathbf{S}_{\mathbf{F}} \mathrm{V}$ (lejtejuol 'to get recognized' )
SG1 met-ek lejtejuol-el
2 tet-ek lejtejuol-el
3 tudel lejtejuol-el ieruuče-ley lejtejuol-el

$\mathrm{SX}_{\mathbf{F}} \mathrm{V}$ (lejtejuol 'to get recognized', uraričiiiče 'teacher', -lek 'instrumental' )

\author{
PL1 mit-ek lejtejuol-el \\ 2 tit-ek lejtejuol-el \\ 3 tittel lejtejuol-yu-l

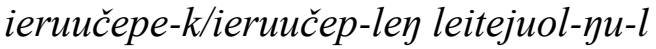
SG1 met uraričiičelek lejtejuod'ey
2 tet uraričiičelek lejtejuod'ek
3 tudel uraričiičelek lejtejuon'
PL1 mit uraričiičelek lejtejuod'eli
2 tit uraričiičelek lejtejuod'emut
3 tittel uraričiičelek lejtejuolyi

As already noted above, the paradigms correspond to those of intransitive verbs. Note how focal constituents occupy the immediate preverbal position, further strengthening the assumption referred to earlier that this slot is reserved for them in TY syntax.

\section{Paradigmatic Deviations}

\subsection{Initial general observations}

The major goal of this paper is to study the mainstream application of the morphological focus system by TY speakers. The very notion of a 'mainstream' implies that there are 'undercurrents' too. Indeed, there is quite some variation in encoding the pragmatic function of focus in the TY speaking community. Some instances of this variation are the subject of attention in the present section.

The investigation of the morphological focus system of TY presented here was performed against the background of Krejnovič's (1958) relevant findings which were taken as the standard. Far from wishing to be prescriptive, I used Krejnovič's (1958) description as an orientation or a reference point because it reflects, after all, the grammar of TY as spoken only half a century ago. The assessing remarks in the following discussion are to be understood as reflecting purely empirical facts and are not to be taken as normative judgments of what is appropriate in the language use and what is not.

As was stated in section 1.3, some informants deviate in their choice of a focus pattern from what could be expected according to Krejnovič's $(1958,1968,1982)$ descriptions. One of them was VNK, who translated the sentences from a diagnostic pilot-questionnaire ${ }^{40}$. His deviant

\footnotetext{
${ }^{39}$ A phonological process described by Krejnovič (1958:146-149) takes effect here conditioning the occurrence of the palatalized plosive as a result of the interaction between the liquid of the passive suffix and the approximant of the person ending. The underlying forms of the latter are -jey, -jek and so forth.

${ }^{40}$ The pilot-questionnaire was prepared by C. Ode. This section contains examples from it.
} 
usage of TY is illustrated by (47a-50a). The constituent which is meant to be focalized, as conditioned by the question (in (47a) and (50a)) or requested explicitly during the elicitation session (49a), is written in capital letters in the translation. The sentence in (48a) is intended as a neutral statement. The morphemes responsible for the focus assignment are highlighted by bold italics.

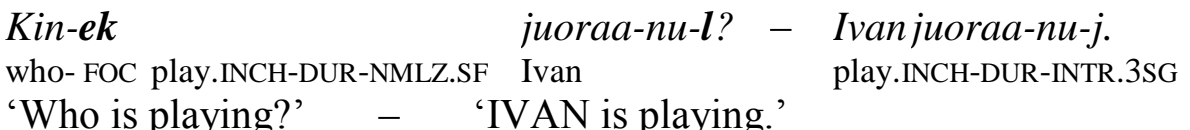

(48a) Ivan laame-ley n'ie-nu-mle.

Ivan dog-FOC call-DUR-TR.3SG.OF

'Ivan is calling up a/the dog.'

(49a) Tit $\boldsymbol{m e}=$ möri-mk? Ivan $\boldsymbol{m} \boldsymbol{e}=$ keweč.

2PL PREDF=hear-TR.2PL Ivan PREDF=go.away.INTR.3SG

'Have you heard? IVAN has left.'

(50a) Neme-le Katja möri-mle? - Katja jaqte-le möri-m.

what-FOC Katia hear-TR.3SG.OF Katia song-ACC hear-TR.3SG

'What did Katia hear?' - 'Katia heard a/the SONG?'

While (48a) and (49a) could, at least theoretically, simply represent the informant's free interpretation of what he was requested to translate, the answers in (47a) and (49a) cannot be accounted for, especially so as the respective questions show the expected focal patterns which should have been repeated in the answers. It is interesting that VNK did decidedly agree with the objection when this nonconformity was pointed out to him and accepted or formed himself the alternative following sentences that were perfectly consistent with Krejnovič's (1958, 1968, 1982) descriptions:

(47b) Ivan juoraa-nu-l.

Ivan play.INCH-DUR-NMLZ.SF

'IVAN is playing.'

(48b) Ivan laame-le n'ie-nu-m.

Ivan dog-ACC call-DUR-TR.3SG

'Ivan is calling up a/the dog.'

(49b) Ivan kewej-l.

Ivan leave-NMLZ.SF

'IVAN has left.'

(50b) Katja jaqte-le möri-mle.

Katia song-FOC hear-TR.3SG.OF

'Katia heard a/the SONG.'

It is confusing that informants sometimes not only produce TY sentences that contradict what is known from the existing descriptions of the language, but also sometimes contradict themselves 
as was the case with VNK. He had translated the sentence pair in (51a) that is structurally identical with the one in $(50 \mathrm{a})$, in a predictable and conformant way:

Ivan kin-ek juo-mele? - Ivan ile-ley juo-mele.

Ivan who-FOC see-TR.3SG.OF Ivan reindeer-FOC see- TR.3SG.OF

'What did Ivan see?' - 'Ivan saw a/the REINDEER.'

Yet, later on he uttered the already discussed sentence pair in (50a).

Inconsistencies occur in many other informants' elicitations. It could almost be said that each and every of them spoke his or her own version of TY. With pragmatics there is always room for some licit variation because the speaker's (and the listener's) subjectivity plays an important role in encoding pragmatic meanings. But the fact that the particular pragmatic function of focus in TY is highly grammaticalized and cannot be treated separately from morphosyntax which is supposed to follow fixed rules, such nonconformities make the established system appear wobbly. The point made here is that although a speaker is free to choose (within certain limits depending on the discourse conditions) which constituent he focalizes, the grammatical means for that would be expected, apart from being systematically applied by the same speaker, to be the same for all speakers. The existing literature does not suggest the existence of alternative encoding patterns of focus.

As a striking example of similar divergences the following sentence pairs in (52a) and (52b) uttered by AGV, the late senior teacher of TY in the Andriushkino school, are quoted.

\section{(52a) Ieriiče neme-le köjle-s-mele? \\ herdsman what-FOC break-CAUS-TR.3SG.OF \\ 'What did the hunter break?'}

\section{Ieriiče lalime-le köjle-s-mele. herdsman sledge-FOC break-CAUS-TR.3SG.OF \\ 'The hunter broke a sledge.'}

This translation is perfectly conformant with the existing descriptions of TY focus system and thus expected. What is confusing about it, is the fact that according to AGV it is, at least as far as the second sentence is concerned, merely a conventional form of an answer which does not accentuate the direct object, which, in turn, totally contradicts all previous accounts of TY focus system. When AGV was asked to reformulate the sentences in such a way that the direct object be logically stressed, she produced the following sentence pair.

(52b) Ieriiče neme-le köjle-su-m?

herdsman what-FOC break-CAUS-TR.3SG

'What did the hunter break?'

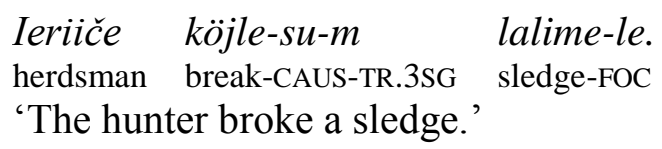


When asked about his opinion on this interpretation of the sentence pairs in (52a) and (52b), GNK, author of many linguistic works and competent native speaker of TY, said that it was incorrect.

The following examples illustrate the differences in encoding AF by different native speakers. The sentences in (53a) and (53b) were elicited from MNT, an elderly female speaker.

(53a) Kin-ek paaj- Ø?

who-FOC hit-AF

'Who hit?'

(53b) Kin-ek laame-le paaj-nun- Ø?

who-FOC dog-ACC hit-HAB-AF

'Who has been beating a/the dog?'

GNK rejects these sentences. In his opinion, the form of question word kinek cannot be used with a bare verb stem. Instead the verb should appear in the form of a nomen actionis, encoded by the flexional affix $-l^{41}$

\section{(54a) Kin-ek paaj-l?}

who-FOC hit-NMLZ.AF

'Who hit?'

(54b) Kin-ek laame-le paaj-nu-l?

who-FOC dog-ACC hit-DUR-NMLZ.AF

'Who is beating a/the dog?'

The sentences in (54a) and (54b), in turn, had been rejected as incorrect by MNT, the woman who uttered the sentences in (53a) and (53b). This mutual rejection holds true for affirmative sentences as well.

Generally, it can be stated that the deviations are of two basic types: the focus pattern of the answer is in conflict with that of the question (deviant form) or the focus patterns in the question and answer are in harmony but their meaning contradicts the available knowledge (deviant interpretation).

Divergences in encoding certain pragmatic meanings manifest themselves not only amongst different speakers but within one and the same speaker as well.

\subsection{Systematic deviations from the standard usage (particular focus articulations)}

Some of the seemingly unwarranted deviations from the common encoding patterns recur, which makes it plausible to assume that they are an integral part of the morphological focus system. This conclusion is most readily applicable to the use of the $\mathrm{BC}$ verb form to express the narrow OF that is characteristic to a varying degree of the speech of several speakers of different age. In PIP, a relatively young TY speaker, it has become the default choice as long as the subject of the sentence is $3^{\text {rd }}$ person although she regards using the formal of pattern in order to actually

\footnotetext{
${ }^{41}$ But see (5c) from Kurilov (2001). It parallels structurally (53a).
} 
encode the pragmatic meaning of OF correct too. For SAA, an older informant, the BC form is the only choice to express the narrow OF in answers irrespective of the person of the subject:

Ieriiče neme-le köjle-s-um? - Ieruuče lalime-le köjle-s-um.

hunter what-FOC break-CAUS-TR.3SG hunter sledge-FOC break-CAUS-TR.3SG

'What did the hunter break?' - 'The hunter broke a/the sledge.'
Tet neme-le

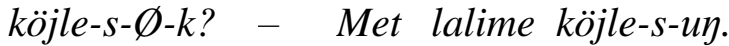
2SG what-FOC break-CAUS-ITRG-2SG 2SG sledge break-CAUS-1SG.TR
'What did you break?' - 'I broke a/the sledge.'

Encoding of a focal object using the BC form of the verb seems to be a relatively widespread strategy. The fact that it has a systematic character and can be found in elderly speakers, indicates that alongside the focus system described by Krejnovič (1958) there has been an alternative focus subsystem in TY involving sentences with transitive verbs as predicates which cannot be explained in terms of language deterioration.

The encoding of the focus articulation $\mathbf{S}_{\mathbf{F}} \mathrm{V}$, on the other hand, is probably the clearest example of how the focus system gradually begins to deteriorate in TY resulting in simplification and generalization.

Among the informants pertaining to the younger generation different ways and degrees of deviation were found. They were least pronounced in PIP who did not use the nominal focal marker in the sentence with the configuration $\mathbf{S}_{\mathbf{F}}(\mathrm{V})$. The next stage was represented by DNT, a slightly younger informant. Not only did she fail to attach the nominal focal marker -ley, but explicitly regarded the form with it as incorrect. Apart from that she used the basic conjugation verb form ${ }^{42}$ in the answer, which should be considered as a rather grave mistake within the focus system of TY as described by Krejnovič $(1958,1982)$ and observed in elder speakers:

\section{Uo aral'we-j. \\ child laugh-INTR.3SG \\ 'A/The child laughs.'}

While the question formed by DNT followed the expected pattern of (3a), the remaining two informants, yet younger IIK $^{43}$ and AST, took the generalization made in (56a) one more logical step further and formed not only the answer but also the question with the basic conjugation verb form. This represents the final stage of deterioration of the focal pattern associated with this particular focus articulation lumping it completely with the basic forms of the verb that do not express any type of focus:

\footnotetext{
${ }^{42}$ It has to be noted that when confronted with the matter DNT admitted that the sentence with the SF form of the predicate and the subject carrying the nominal focus marker could be formed and was more precise. However, she regarded it only as an alternative to her own sentence which she continued to see as correct.

${ }^{43}$ IIK did use the nominal focal marker -ley with the subject in the answer, though. He made in connection with this focus articulation a few confusing remarks. Firstly, he admitted the possibility of usage of the SF form of the predicate along with that of the basic conjugation in the answer. The former would then mark a male referent of the subject and the latter would refer to a female one. This is a very odd comment, to say the least, since there is no grammatical category of gender in TY. Secondly, in the answer with the configuration $\mathbf{S}_{\mathbf{F}}(\mathrm{V})$ he uttered two forms. The one with the nominal focal marker -ley would designate a referent within the visual field of the interlocutors; the one without it would stand for an invisible referent.
} 
(56b) Kin-ek aral'waa-nu-j?

who-FOC laugh.INCH-DUR-INTR.3SG

'Who is laughing?'

Uo ayal'waa-nu-j.

child laugh.INCH-DUR-INTR.3SG

'A/The child is laughing.'

\section{Conclusion}

The author hopes that some of the findings or remarks made in this article will have some importance for the theory of information structure generally. However, as it was conceived primarily as a descriptive contribution, the author is content to have filled a few gaps in the description of the focus system of TY. It has been determined what focal patterns are employed in sentences with multiple focal constituents and three hierarchies in the actual morphological focalizing valid in such instances have been established. The encoding patterns of SAs with multiple pragmatic functions have been systematically analyzed and presented. The distribution of the verbal clitic $m e$ has been further investigated, which resulted in several interesting findings and, hopefully, led to a better understanding of the functions of this somewhat enigmatic device of the TY grammar. It has been proven that the focus markers of TY are multifunctional, fulfilling also the role of contrast markers and serving as signals of emphasis.

Apart from that, it has been established with all certainty that the morphological focus system of TY permeates the whole language being fully operational in negative sentences and in the passive voice.

Detailed standardized elicitations from a relatively large number of informants have revealed the existence of a focus subsystem which has gone unnoticed until now. Maybe there are several such subsystems. It is not excluded that they overlap and form a continuum. Further research is needed to clarify this. Unfortunately, changes of a different sort have been detected too unambiguous signs of the deterioration of the once attested focus system in younger speakers. Generally, it can be stated that there seems to be a fairly high degree of instability in some TY speakers' choices of a certain focal pattern.

Further contributions on TY focus system are welcome, especially on the topics illustrating details of the interaction of morphology and syntax/prosody in encoding this pragmatic function, focus in copular sentences, focalizing nominal modifiers etc.

\section{Appendix}

\section{Structure of the basic questionnaire:}

SV $\mathbf{V}_{\mathbf{F}}$ : What is $\mathrm{S}$ doing? $-\mathrm{S} \mathrm{V}_{\text {INTR }}$.

AOV $\mathbf{V}_{\mathbf{F}}$ : What did A do with O? - A $V_{\mathrm{TR}} \mathrm{O}$.

$\mathrm{S}_{\mathrm{F}} \mathrm{V}$ : Who $\mathrm{V}_{\text {INTR }}$ ? $-\mathrm{S} \mathrm{V}_{\text {INTR }}$.

$\mathbf{A}_{\mathrm{F}} \mathrm{OV}$ : Who $\mathrm{V}_{\mathrm{TR}} \mathrm{O}$ ? - $\mathrm{A}_{\mathrm{TR}} \mathrm{O}$.

AVO $\mathbf{O}_{\mathbf{F}}$ : What did A $V_{T R}$ ? - A $V_{T R} O$.

$\mathbf{A}_{\mathbf{F}} \mathrm{OV}_{\mathbf{F}}$ : What happened to $\mathrm{O}$ ? $-\mathrm{A}_{\mathrm{TR}} \mathrm{O}$. 
$\mathrm{AO}_{\mathbf{F}} \mathbf{V}_{\mathbf{F}}$ : What did $\mathrm{A}$ do? - A $\mathrm{V}_{\mathrm{TR}} \mathrm{O}$.

$\mathrm{A}_{\mathrm{F}} \mathbf{O}_{\mathrm{F}} \mathrm{V}$ : What did one give to $\mathrm{X}$ ? - A gave $\mathrm{X} \mathrm{O}$.

$\mathbf{S}_{\mathbf{F}} \mathbf{V}_{\mathbf{F}} / \mathbf{A}_{\mathbf{F}} \mathbf{O}_{\mathbf{F}} \mathbf{V}_{\mathbf{F}}$ : What happened?/Well, what's new? - $\mathrm{S} \mathrm{V}_{\mathrm{INTR}},\left(\mathrm{V}_{\mathrm{INTR}} \ldots\right) . / \mathrm{A} \mathrm{V}_{\mathrm{TR}} \mathrm{O},\left(\mathrm{V}_{\mathrm{TR}} \mathrm{O} \ldots\right)$

Peripheral constituents: e.g. Where did $A V_{T R} O$ ?/When did $S V_{\text {INTR }}$ ? $-A V_{T R} O$ in $X . / S V_{\text {INTR }}$ $\mathrm{X}$.

Structure of the questionnaire for studying contrast (sketched for predicate contrast):

Focus/Contrast

Replacing: S V $\mathrm{INTR}_{\text {IN }}-\mathrm{No}, \mathrm{S} \mathrm{V}_{\mathrm{INTR} 2}$.

Expanding: $\mathrm{S} \mathrm{V}_{\mathrm{INTR} 1 \cdot}-\mathrm{S}$ also $\mathrm{V}_{\text {INTR2 }}$.

Topic/Contrast

Rejecting: $\mathrm{S} \mathrm{V}_{\text {INTR }}-\mathrm{No}, \mathrm{S}$ does not $\mathrm{V}_{\text {INTR }}$.

Restricting: $S \mathrm{~V}_{\text {INTR1 }}$ and $\mathrm{V}_{\text {INTR2. }}-\mathrm{No}$, $S$ only $\mathrm{V}_{\text {INTR1. }}$.

Selecting: Does $S \mathrm{~V}_{\text {INTR1 }}$ or $\mathrm{V}_{\text {INTR2}}$ ? $-\mathrm{S} \mathrm{V}_{\mathrm{INTR} 1}$.

Topic/Contrast + Focus/Contrast

Parallel: e.g. $S_{1}$ and $S_{2}$ COP. $-S_{1} V_{\text {INTR1 }}$ and $S_{2} V_{\text {INTR2 }}$.

Rejecting + Replacing: $S V_{\text {INTR1. }}-$ No, $S$ does not $V_{\text {INTR1 }}, S V_{\text {INTR2. }}$.

Expanding (fuller form): $S V_{\text {INTR1. }}-\mathrm{S}$ not only $\mathrm{V}_{\text {INTR1 }}$ but also $\mathrm{V}_{\text {INTR2. }}$

Topic/Contrast + Topic/Contrast

Restricting (fuller form): $S \mathrm{~V}_{\text {INTR1 }}$ and $\mathrm{V}_{\text {INTR2. }}-\mathrm{No}, \mathrm{S}$ does not $\mathrm{V}_{\text {INTR } 1}$, he only $\mathrm{V}_{\text {INTR2. }}$.

\author{
Abbreviations: \\ 1,2,3 - first, second, third person \\ ABL - ablative \\ ACC - accusative \\ ADV - adverb \\ $\mathrm{AF}-\mathrm{A}$-focus \\ ATTR - attributive \\ AUG - augmentative \\ $\mathrm{BC}$ - basic conjugation \\ $\mathrm{BF}$ - basic form \\ CAUS - causative \\ COM - comitative \\ COP - copula \\ CVB - converb \\ DAT - dative \\ DEM - demonstrative \\ DIM - diminutive \\ DUR - durative \\ EMPH - emphatic \\ FOC - focus
}




$$
\begin{aligned}
& \text { FUT - future } \\
& \text { GEN - genitive } \\
& \text { HAB - habitualis } \\
& \text { IMP - imperative } \\
& \text { INCT - incentive } \\
& \text { INCH - inchoative } \\
& \text { IDF - indefinite } \\
& \text { INTR - intransitive } \\
& \text { ITRG - interrogative } \\
& \text { LOC - locative } \\
& \text { NVIS - nonvisual } \\
& \text { NEG - negative } \\
& \text { NMLZ - nominalizer } \\
& \text { OBL - obligative } \\
& \text { OF - object focus } \\
& \text { PL - plural } \\
& \text { PASS - passive } \\
& \text { POSS - possessive } \\
& \text { PREDF - predicate focus } \\
& \text { PTCP - participle } \\
& \text { PURP - purpositive } \\
& \text { RECP - reciprocal } \\
& \text { RES - resultative } \\
& \text { RLN - relational } \\
& \text { SEM - semelfactive } \\
& \text { SF - S-focus } \\
& \text { SG - singular } \\
& \text { TR - transitive }
\end{aligned}
$$

\section{References}

\section{Primary Sources}

Kurilov, G.N. 1991. Predanija o drevnich ljudjach. Čuol'è n'ièd'ilpè. Chal'archaa. Rozovaja čajka 1/91 [Legends about ancient people. Čuol'è n'ièd'ilpè. Chal'archaa. Pink gull 1/91] Jakutsk: Rozovaja čajka.

Kurilov, N.N. 1994. Čuynul kinigè. 3 klasnin'. Jakutsk: Rozovaja čajka.

\section{Secondary Sources}

Ard, Josh. 1982. Auxiliary do: support or emphasis. Linguistics: An Interdisciplinary Journal of the Language Sciences 20/5-6.445-466.

Chafe, Wallace. 1976. Givenness, Contrastiveness, Definiteness, Subjects, Topics, and Point of View. Subject and Topic, ed. By Charles N. Li, 25-55, New York: Academic.

Comrie, Bernard. 1981a. The languages of the Soviet Union. Cambridge: Cambridge University Press. 
-----. (1992). Focus in Yukagir (Tundra dialect). The Non-Slavic Languages of the USSR, ed. by Howard I. Aronson, 55-70, Chicago: University of Chicago.

Dik, Simon C. 1978. Functional grammar. Amsterdam: North-Holland Publishing Company.

----- 1997. The theory of functional grammar. 1. The structure of the clause. $2^{\text {nd }}$ ed. Berlin: Mouton de Gruyter.

Donskoj, F. S. 1996. Naselenie: rasselenie i demografičeskaja situacija. Problemy vozroždenija isčezajuščich jukagirov, I. E. Tomskij (otv. red.) [Population: distribution and demographic situation. Issues in the revival of the disappearing Yukaghirs, ed. by I. E. Tomskij], 22-33, Jakutsk: Severoved.

Fortescue, Michael. 1996. Grammaticalized focus in Yukaghir: Is it really grammaticalized and is it really focus? Content, Expression and Structure: Studies in Danish Functional Grammar, ed. by Elisabeth Engberg-Pedersen et al. 17-38, Amsterdam: Benjamins.

Hengeveld, Kees and Mackenzie, J. Lachlan. 2008. Functional discourse grammar: a typologically-based theory of language structure. Oxford: Oxford University Press.

Harms, Robert T. 1977. The Uralo-Yukaghir focus system: a problem in remote genetic relationship. Studies in descriptive and historical linguistics: Festschrift for Winfred P. Lehmann, ed. by Paul J. Hopper, 301-306, Amsterdam: Benjamins.

Krejnovič, E.A. 1958. Yukagirskij jazyk. [Yukaghir language.] Moscow, Leningrad: Izdateljstvo Akademii Nauk SSSR.

-----. 1968. "Yukagirskij jazyk". Jazyki narodov SSSR, t. V, V.V. Vinogradov et al. (glavn. red.) ["Yukaghir language." Languages of the Peoples of the USSR, Vol. V, ed. by V.V. Vinogradov et al.], 435-452, Leningrad: Nauka.

-----. 1982. Issledovanija i materialy po jukagirskomu jazyku. [Studies and materials on Yukaghir language.] Leningrad: Nauka.

Krifka, Manfred 2008. Basic Notions of Information Structure. Acta Linguistica Hungarica: An International Journal of Linguistics 55/3-4.243-276.

Kurilov, G. N. 1996. Programma vozroždenija jazyka i kul'tury jukagirov. Problemy vozroždenija isčezajuščich jukagirov, I. E. Tomskij (otv. red.) [Revitalization strategy for Yukaghir language and culture. Issues in the revival of the disappearing Yukaghirs, ed. by I. E. Tomskij], 112-124, Jakutsk: Severoved.

-----. 2001. Jukagirsko-russkij slovar'. [Yukaghir-Russian dictionary.] Novosibirsk: Nauka.

----. 2005. Fol'klor jukagirov. [Yukaghir folklore.] Novosibirsk: Nauka

----. 2006. Sovremennyj jukagirskij jazyk: Učebnoe posobie. [Modern Yukaghir: Manual.] Jakutsk: Ofset.

Lambrecht, Knud. 1994. Information structure and sentence form. Topic, focus and the mental representations of discourse referents. Cambridge: Cambridge University Press.

Lewis, David. 1979. Scorekeeping in a language game. Journal of Philosophical Logic 8/1.339359.

Maslova, Elena. 1989a. Sootnošenie kommunikativnoj i sintaksičeskoj struktur v prostom predloženii Jukagirskogo jazyka. [The relation between communicative and syntactic structure in Yukaghir clause.] Ph.D. dissertation. St. Petersburg: Institute of Linguistic Studies.

----- 1997. Yukagir focus system in a typological perspective. Journal of Pragmatics 27.457-75.

-----. 2003c. Tundra Yukagir. München: LINCOM Europa. 
-----. 2005. Information structure in Tundra Yukagir and typology of focus structures. Les langues ouraliennes aujourd'hui: Approche linguistique et cognitive, ed. by Jocelyne Fernandez Vest, 599-610, Paris: Honoré Champion.

-----. 2006. Information focus in relational clause structure. Voice and grammatical relations, ed. by Tasaku Tsunoda and Taro Kageyama, 175-194, Amsterdam: Benjamins.

Matić, Dejan and Nikolaeva, Irina. 2008. Predicate focus and the particle mə(r)= in Tundra Yukaghir. Paper presented at the Workshop Predicate Focus, Verum Focus, Verb Focus: Similarities and Differences, University of Potsdam, November 2008.

Nikolaeva, Irina. 2002. Yukaghir. (Unpublished manuscript)

Nikolaeva, I. A. and Chelimskij, E. A. 1996. Jukagirskij jazyk. Jazyki mira. Paleoaziatskie jazyki, A.P. Volodin (otv. red), N. B. Vachtin and A. A. Kibrik [Yukaghir language. Languages of the world. Paleoasian languages, ed. by A.P. Volodin, N. B. Vachtin and A. A. Kibrik], 155168, Moskva: Indrik.

Stalnaker, Robert C. 1974. Pragmatic presupposition. Semantics and philosophy, ed. by Milton K. Munitz and Peter K. Unger, 197-213, New York: New York University Press.

Tomskij, I. E. 1996. Problemy vozroždenija isčezajuščich jukagirov. [Issues in the revival of the disappearin Yukaghirs.] Jakutsk: Severoved.

Author's Contact Information:

Mark Schmalz

Universiteit van Amsterdam

Departement Taal- en letterkunde

Spuistraat 210

1012 VT Amsterdam, The Netherlands

m.schmalz@uva.nl 